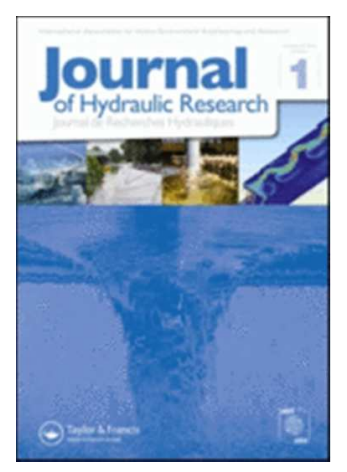

\title{
On the generation of regular long waves in the Particle Finite Element Method
}

\begin{tabular}{|r|l|}
\hline Journal: & Journal of Hydraulic Research \\
\hline Manuscript ID & TJHR-2015-0038.R3 \\
\hline Manuscript Type: & Research paper \\
\hline Date Submitted by the Author: & n/a \\
\hline Complete List of Authors: & $\begin{array}{l}\text { Castro Oliveira, Tiago; Federal University of Espírito Santo, Environmental } \\
\text { Engineering Department } \\
\text { Sanchez-Arcilla, Agustin; LIM/UPC, } \\
\text { Gironella, Francesc Xavier; LIM/UPC, } \\
\text { Madsen, Ole; Massachusetts Institute of Technology (MIT), Civil \& } \\
\text { Environmental Engineering }\end{array}$ \\
\hline Keywords: & $\begin{array}{l}\text { Gravity waves, Hydraulic models, Particle Finite Element Method, Solitary } \\
\text { waves, two-dimensional numerical simulation, CFD, Cnoidal waves }\end{array}$ \\
\hline JHR Keywords: & $\begin{array}{l}\text { Gravity waves < Hydrodynamic waves, Solitary waves < Hydrodynamic } \\
\text { waves, Hydraulic models < Instrumentation, measurements and } \\
\text { experimental methods, Coastal engineering < Applied fluid mechanics and } \\
\text { hydraulic engineering, Coastal hydraulics < Environmental Fluid Mechanics }\end{array}$ \\
\hline
\end{tabular}


On the generation of regular long waves in the Particle Finite Element Method

TIAGO C. A. OLIVEIRA, Postdoctoral fellow, Environmental Engineering Department, Federal University of Espirito Santo, Av. Fernando Ferrari, 514 - Campus Universitário Goiabeiras, CEP 29060-970, Vitoria (ES), Brazil

Email: tiago.c.oliveira@ufes.br (authorfor correspondence)

AGUSTÍN SANCHEZ-ARCILLA (IAHR Member), Professor, Laboratori d'Enginyeria Maritima, ETSECCPB, Universitat Politècnica de Catalunya, Spain

Email:agustin.arcilla@upc.edu

XAVIER GIRONELLA, Professor, Laboratori d'Enginyeria Marítima, ETSECCPB, Universitat Politècnica de Catalunya, Spain

Email:xavi.gironella@upc.edu

OLE S. MADSEN, Professor, Parsons Laboratory, Department of Civil and Environmental Engineering, Massachusetts Institute of Technology, USA

Email:osm@mit.edu

Running Head: Regular long waves in the PFEM.

URL: http://mc.manuscriptcentral.com/jhr 


\title{
On the generation of regular long waves in the Particle Finite Element Method
}

\begin{abstract}
Most of the coastal hydraulic studies in physical and numerical wave flumes (NWF) require the correct generation of non-linear, long period waves in intermediate and shallow water. In this paper, the ability to generate such long waves in a NWF based on the Particle Finite Element Method (PFEM) is analyzed. Wavemaker theories based on Stokes Second Order wave theory, Cnoidal wave theory and Solitary wave theory are implemented in the NWF through a piston type paddle boundary conditions. An assessment of the capability and robustness of generation and propagation of long waves in the NWF is carried out. Numerical results are compared to theoretical results and data from specific physical tests. Results indicate that regular long waves of permanent form can be generated in a NWF based on the PFEM using the implemented wavemaker theories. However, a compromise has to be made between the target wave conditions and the validity field of each wavemaker theory when choosing a wavemaker theory.

Keywords: Gravity waves; Hydraulic models; Particle Finite Element Method; Solitary waves; two-dimensional numerical simulation
\end{abstract}

\section{Introduction}

Physical wave flumes have been widely applied in laboratory studies dealing with the hydraulic and stability behavior of coastal structures, beach profile evolution and other related coastal phenomena involving waves. Most of these hydraulic studies require the generation of long waves in intermediate and shallow water wave conditions. Normally for these wave conditions we have high Ursell numbers $\left(U_{r}=H L^{2} / h^{3}, H\right.$ wave height; $L$ wave length; $h$ water depth) and low relative water depths $(h / L)$ that means the presence of highly nonlinear waves. Therefore the accuracy of laboratory results depends on the accuracy of and ability to generate robustly such energetic long waves.

The most common way to generate waves in physical flumes is by moving a paddle in contact with the water volume (Hughes, 1993; Hudspeth and Guenther, 2009). An analytical solution for waves generated by piston and flap paddles based on linear wave theory was derived by Biesel and Suquet (1951).

The appearance of second harmonic free waves for some wave conditions when moving the paddle sinusoidaly were reported by different authors (Morison and Crooke, 1953; Goda, 1967; Le Méhauté et al., 1968; Galvin, 1968; Iwagaki and Sakai, 1970).

The amplitude of the second harmonic free and bound wave has been derived by Madsen 
(1971) under the assumption of relative long waves $(h / L \leq 0.1)$ and for waves generated by a piston-type wavemaker. Goda (1997) solved the amplitude and phases of secondary and tertiary bound and free nonlinear components as well as the interference waves with a perturbation technique for a piston-type wavemaker.

In order to prevent the generation of unwanted secondary waves several authors proposed different solutions for second order wavemaker generation theories. Using Lagrangian coordinates Fontanet (1961) gave a complete solution to the problem. Madsen (1971) derived an approximate solution giving an explicit expression of the wave paddle motion. Daugaard (1972) gave other approximate second order solution for a piston paddle. For a wave paddle that is hinged at or below the bottom of the flume Flick and Guza (1980) found a solution. Hudspeth and Sulisz (1991) gave the complete analytical solution for a generic planar wave paddle moving in a monochromatic oscillation. For a piston and a hinged wave paddle, Schäffer (1996) gave the complete solution including superharmonics (sum frequencies) and subharmonics (difference frequencies). Second order wavemaker theories were also developed for the generation of multidirectional waves in basins (Steenberg and Schäffer, 2001; Schäffer and Steenberg, 2003).

On the other hand, wavemaker models based on other wave theories have been developed to generate waves with a constant profile for a given high steepness, $H / L$, or a very small relative depth, $h / L$. Goring (1979) developed a wavemaker theory based on cnoidal wave theory using a piston type wave board. This theory was developed in order to accurately simulate tsunami waves. Based on stream function wave theory Zhang and Schäffer (2007) developed a wavemaker theory that can be used to generate even higher order waves. In coastal engineering, the solitary wave is commonly used to represent certain characteristics of tsunamis, storm surges, and other long free surface oscillations. To generate a solitary wave using a piston-type wavemaker, the plate displacement as a function of time was determined by Goring (1979). Later on, other wavemaker theories for the generation of solitary waves were presented (Synolakis, 1990; Guizien and Barthélémy, 2002; MalekMohammadi and Testik, 2010). Several studies focus on the investigation of solitary wave properties were performed based on the generation of solitary waves in experimental facilities (e.g.; Liu et al., 2006; Chen et al., 2015).

In the last three decades, there have been important developments in numerical models dealing with fluid-solid interactions. This has gone in parallel with an increased study of wave-structure interaction problems in NWFs. The NWFs presented in the scientific literature can be grouped based on their basic equations and numerical schemes. NWF based on Non Linear Shallow Water (NLSW) equations applied to maritime structures were presented by 
van Gent (1994), Dodd (1998) and Hu et al. (2000). The linear and fully nonlinear potential wave theory were successful used as NWF to study a wide range of wave processes including the runup, reflection and shoaling of solitary waves (e.g. Grilli and Svendsen, 1991; Grilli et al. 1994; Wu et al., 2014). Several coastal engineering studies with NWF based on the Volume of Fluid (VOF) technique for solving Navier-Stokes equations for incompressible fluids can be found in the literature. Van Gent et al. (1994) presented a VOF model that can simulate plunging wave breaking into porous structures. Lin and Liu (1998) described the development of a VOF type model based on the Reynolds-Averaged Navier-Stokes equations to study the evolution of wave groupiness, shoaling, and breaking in the swash zone. The IH2D VOF model was successfully applied to a variety of wave structure interaction studies (Lara et al., 2006) including wave vegetation interaction simulations (Maza et al, 2013). The use of the mesheless Smooth Particle Hydrodynamics (SPH) technique in coastal engineering began at the end of the 90's (Monaghan and Kos, 1999). Dalrymple and Rogers (2006) studied the plunging wave breaker using a model based on the SPH method. Shao et al. (2006) presented an incompressible SPH model to study wave-coastal structure interaction problems.

The Moving Particle Semi-implicit (MPS) method is another meshless technique that has been used in NWFs to study physical phenomena such as wave breaking (Koshizuka et al. 1998) or wave impact pressures (Khayyer and Gotoh, 2009). Recent GPU (Graphics Processing Unit) versions of SPH (Herault et al., 2010; Gomez-Gesteira et al., 2012; Domínguez, et al., 2013) and MPS (Hori et al., 2011) models represent an important improvement in the reduction of computational time to allow the simulation of more realistic cases.

The Particle Finite Element Method (PFEM) introduced by Idelsohn et al. (2003a) has also been used as the basis for a NWF (Oliveira et al., 2009a; Oliveira et al., 2012). Oliveira et al. (2009a) validated the generation of regular waves in a NWF based on PFEM using a first order wavemaker theory. The authors were able to generate a wide number of short wave conditions $(0.14<h / L<0.23)$ with low Ursell numbers $\left(0.26<U_{r}<9.20\right)$. Oliveira et al. (2012) simulated wave overtopping for impermeable maritime structures using a first order wavemaker theory to generate waves.

A NWF should be an accurate representation of a physical wave flume (eventually of a natural beach profile) and the correct generation of waves becomes a fundamental requirement. In the NWF based on SPH, MPS and PFEM waves are generated in a way similar to physical flumes. In these cases, the most common way to generate waves is through the movement of a paddle that is generally located at one of the ends of the flume. 
In recent years, there has been an increase interest in the use of the PFEM to study a variety of hydraulic problems involving large free surface motion (e.g. Rossi and Oñate, 2010; Larese et al., 2012; Becker et al., 2015; Dang and Meschke, 2014; Gimenez and González, 2015). Although a NWF based on PFEM can be a powerful tool to study hydraulic phenomena involving waves, a boundary condition to generate waves in intermediate and shallow water conditions needs to be developed.

The main objectives of this work are: 1) to study the nonlinear phenomena that occur when regular long waves are generated in a NWF based on the PFEM by a sinusoidal wavemaker movement 2) to introduce the ability to generate regular long waves in a NWF based on the PFEM. In order to achieve these objectives five steps were established. First, a series of small scale physical tests were carried out focusing on the generation of regular long waves using a first order wavemaker theory. In a second step, physical test conditions were reproduced in the NWF. The behavior of free harmonics in the physical and numerical flumes was compared and the NWF was calibrated. In a third step, the piston paddle wavemaker theories based on stokes second order wave theory (Madsen, 1971), cnoidal wave theory (Goring, 1979) and solitary wave (Goring, 1979) were implemented in the NWF. In the fourth step, the wave conditions tested in the steps before were generated in the NWF using the new implemented wavemaker theories. The elimination of free harmonics was analyzed subsequently. In the fifth step, two cases of regular long waves, that can be difficult to simulate in physical flumes due to limitations in paddle stroke and velocity, were simulated and analyzed in the NWF.

The layout of this paper is the following: Section 2 describes the main characteristics of the numerical technique PFM. In Section 3 the wavemaker theories used in this study are summarized. In section 4 the small scale physical tests are presented. Section 5 is dedicated to all numerical simulations including the wavemaker theories that were implemented in the NWF. In this section there is some discussion of results and model performance. The paper ends with the main conclusions and recommendations for further research.

\section{The Particle Finite Element Method with a free-surface}

The PFEM is now a well-known method in the scientific literature (Idelsohn et al., 2003a, Oñate et al., 2004, Oñate et al., 2008). However, some specific key features of the PFEM are also included in this paper for completeness. The PFEM solves the fluid mechanics equations by a Lagrangian approach. It is a particular class of Lagrangian flow formulations, developed to solve free surface flow problems involving large deformations of the free surface, as well as the interaction with rigid bodies. The finite element method (FEM) is used to solve the continuum equations in the fluid and solid domains. The PFEM treats the mesh nodes in the 
fluid and solid domains as particles, which can freely move and even separate from the main fluid domain representing, for instance, the effect of water drops or melted zones. The data between two consecutive time steps is only transferred through nodes, because elements are created again at every time step by a re-meshing process with new conectivities.

In the PFEM the mass conservation and momentum conservation equations (Navier-Stokes) in the final $x_{i}$ position are written as follows:

$$
\begin{gathered}
\frac{D \rho}{D t}+\rho \frac{\partial u_{i}}{\partial x_{i}}=0 \\
\rho \frac{D u_{i}}{D t}=-\frac{\partial}{\partial_{x_{i}}} p+\frac{\partial}{\partial_{x_{j}}} \tau_{i j}+\rho f_{i}
\end{gathered}
$$

where $\rho$ is the density, $u_{i}$ are the cartesian components of the velocity field, $p$ the pressure, $\tau_{i j}$ the deviatoric stress tensor, $f_{i}$ the source tensor (usually the gravity), $\frac{D}{D t}$ represents the total or material time derivate.

For Newtonian fluids the stress tensor $\tau_{i j}$ may be expressed as a function of the velocity field through the viscosity $\mu$ by:

$$
\tau_{i j}=\mu\left(\frac{\partial u_{i}}{\partial_{x_{j}}}+\frac{\partial u_{j}}{\partial_{x_{i}}}-\frac{2}{3} \frac{\partial u_{l}}{\partial_{x_{l}}} \delta_{i j}\right)
$$

For near incompressible flows $\frac{\partial u_{i}}{\partial x_{i}} \ll \frac{\partial u_{k}}{\partial x_{l}}$ and thus:

$$
\frac{2 \mu}{3} \frac{\partial u_{l}}{\partial_{x_{l}}} \approx 0
$$

Then, the stress tensor $\tau_{i j}$ can be written as:

$$
\tau_{i j} \approx \mu\left(\frac{\partial u_{i}}{\partial_{x_{j}}}+\frac{\partial u_{j}}{\partial_{x_{i}}}\right)
$$

Using Eq. (5) the momentum conservation equation can be written as:

$$
\rho \frac{D u_{i}}{D t} \approx-\frac{\partial}{\partial_{x_{i}}} p+\mu \frac{\partial}{\partial_{x_{j}}}\left(\frac{\partial u_{i}}{\partial_{x_{j}}}\right)+\rho f_{i}
$$

Traditionally, computational fluids dynamics problems have been solved by models based on Eularian or ALE formulations. In Eularian formulations the non-linearity is explicitly presented in the convective terms. In the PFEM Lagrangian formulation the non-linearity is due to the fact the momentum equation is written in the final positions of the particles. 
The Navier-Stokes equations are time dependent and thus a temporal integration needs to be carried out. The fractional-step method proposed in Codina (2001) is used in PFEM for the time solution. Even when using an implicit time integration scheme, incompressibility introduces some wiggles in the pressure solution which must be stabilized to avoid pressure oscillations in some particular cases. In the PFEM a simple and effective procedure to derive a stabilized formulation for incompressible flows based on the so-called Finite Calculus (FIC) formulations (Oñate, 2000) is used.

In order to solve the governing equations that represent the continuum particles must be connected. A mesh discretizing the fluid and solid domains must be generated in order to solve the governing equations for both the fluid and solid problems in the standard FEM fashion. A fast regeneration of the mesh at every time step on the basis of the position of the nodes in the space domain is used. A mesh is generated at each time step using the so-called Extended Delaunay Tessellation (EDT) (Idelsohn et al., 2003b). The EDT allows the generation of non standard meshes combining elements of arbitrary polyhedrical shapes (triangles, quadrilaterals and other polygons in the 2D case) in a computing time of order $n$, where $n$ is the total number of nodes in the mesh. One of the key to solve a fluid mechanics problem using a Lagrangian formulation is to generate efficiently the shape functions to approximate the unknown spatial variation. In the PFEM the interpolation function used by the Meshless Finite Element Method (MFEM) (Idelsohn et al., 2003c) is applied. EDT together with the MFEM are the main keys to make the PFEM a useful tool. The CPU required for meshing grows linearly with the number of nodes. However, Oñate et al., (2008) found that the CPU time for solving the equations exceeds that required for meshing as the number of nodes increases. As in the standard FEM, the quality of the numerical solution depends on the discretization chosen. Adaptive mesh refinements techniques can be used to improve the solution in zones of special interest.

It must be noted that the information in the PFEM is typically nodal-based, i.e. the element mesh is mainly used to obtain the values of the state variables (i.e. velocities, pressure, viscosity, etc.) at the nodes. A difficulty arises in the identification of the boundary of the domain from a given collection of nodes. Indeed the boundary can include the free surface of the fluid and the individual particles moving outside the fluid domain. For this purpose the Alpha Shape technique (Edelsbrunner and Mucke, 1994) has been used to identify the boundary nodes.

In summary the main difference between the PFEM and the classical FEM is the remeshing technique and the evaluation of the boundary position at each time step. The remaining steps in the computation are equivalent to those of the classical FEM. 


\section{Wavemaker theories}

The following sections show different wave generation equations for theoretical waves generated on the test-section side of the paddle.

\subsection{First order wave generation}

The free surface profile of a simple sinusoidal wave as a function of horizontal distance $x$ and time $\mathrm{t}$ is given by:

$$
\eta=a \cos \left(k_{0} x-\omega t\right)
$$

where $a$ is the wave amplitude, $k_{0}$ is the wave number $\left(k_{0}=2 \pi / L\right), \omega$ the angular frequency $(\omega=2 \pi / T), L$ is the wave length and $T$ the wave period.

By means of the first order wavemaker theory a simple sinusoidal wave can be generated in a wave flume (Hughes, 1993). For a piston paddle type the paddle displacement can be obtained as was proposed by Biesel and Suquet (1951):

$$
X_{0}(t)=2 a\left(\frac{\sinh 2 k_{0} h+2 k_{0} h}{8 \sinh ^{2} k_{0} h}\right) \sin \omega t
$$

where $h$ is the water depth in front of the paddle.

Madsen (1970) proposed that the leakage around the paddle will decrease the amplitude of the generated waves by an amount $\Delta a$ which may be found from:

$$
\frac{\Delta a}{a}=-\left(2.22 \sqrt{\frac{1}{\cosh k_{0} h}} \frac{\Delta_{B}}{h} \frac{K_{0} h}{\sinh k_{0} h}+1.11 \frac{\Delta_{S}}{b}\left(1+\sqrt{\frac{1}{\cosh k_{0} h}}\right)\right) \frac{\sqrt{g a}}{U}
$$

where $\Delta_{B}$ is the gap between the wavemaker and the bottom, $\Delta_{S}$ is the gap between the sidewalls and the wavemaker, $b$ is the width of the wave tank, $U$ is the amplitude of the sinusoidal wavemaker velocity and $g$ is the gravity. The basic assumption in the derivation of Eq. (9) is that the progressive waves being generated are moderately long, i.e. $h / L<1 / 6$, since only then can the evanescent modes be assumed small. Another assumption is that the wavemaker generates waves in both directions, i.e. one propagating into the test section in front and another one (out of phase with the former) in the region behind the wavemaker.

\subsection{Second order wave generation}

According to Madsen (1971) in physical terms periodic progressive relatively long waves generated by a wavemaker moving in a sinusoidal way can be expressed as:

(1) A first harmonic linear wave of amplitude $a$ and wave number $k_{0}$ 
(2) A second harmonic coupled with the first harmonic to give the second Stokes' wave corresponding to the linear solution of amplitude $a_{s}^{(2)}$ and wave number $2 k_{0}$

(3) A second harmonic free wave of small amplitude $a_{f}^{(2)}$ and wave number $k_{f}^{(2)}$

And the surface elevation at a fixed value of $x$ can be expressed as:

$$
\begin{aligned}
\eta=\eta^{(1)}+\eta_{s}^{(2)} & +\eta_{f}^{(2)} \\
& =-a \sin \left(k_{0} x-\omega t\right)-a_{s}^{(2)} \cos 2\left(k_{0} x-\omega t\right) \\
& +a_{f}^{(2)} \cos \left(k_{f}^{(2)} x-2 \omega t\right)
\end{aligned}
$$

The ratio of the amplitudes of the second and first harmonic, $a_{s}^{(2)} / a$, is clearly a measure of the meaningfulness of a Stokes second order solution for a progressive wave. For long waves this ratio may be written as:

$$
\frac{a_{s}^{(2)}}{a}=\frac{3 U_{r}}{32 \pi^{3}}
$$

The amplitude of the second harmonic free wave, $a_{f}^{(2)}$, is given by:

$$
a_{f}^{(2)}=\frac{1}{2} a^{2} \frac{\operatorname{coth} \mathrm{k}_{0} \mathrm{~h}}{\mathrm{~h}}\left(\frac{3}{4 \sinh ^{2} k_{0} h}-\frac{n_{1}}{2}\right) \frac{\tanh k_{f}^{(2)} h}{n_{2}}
$$

where:

$$
n_{1}=\frac{1}{2}\left(1+\frac{2 k_{0} h}{\sinh 2 k_{0} h}\right) ; \quad n_{2}=\frac{1}{2}\left(1+\frac{2 k_{f}^{(2)} h}{\sinh 2 k_{f}^{(2)} h}\right)
$$

The second harmonic free wave may be eliminated when the wavemaker motion is prescribed as:

$$
\begin{gathered}
X_{2}(t)=2 a\left(\frac{\sinh 2 k_{0} h+2 k_{0} h}{8 \sinh ^{2} k_{0} h}\right) \sin \omega t+\frac{a^{2}}{8 h}\left(\frac{3 \cosh k_{0} h}{\sinh ^{3} k_{f}^{(2)} h}\right. \\
\left.-\frac{\sinh 2 k_{f}^{(2)} h+2 k_{f}^{(2)} h}{2 \sinh ^{2} k_{f}^{(2)} h}\right) \sin 2 \omega t
\end{gathered}
$$

where $X_{2}$ is the paddle position given by second order wavemaker theory.

The generated waves should therefore be purely progressive and of permanent form. 
According to Madsen (1971) for accurate second order solution approximation it should have $U_{r} \ll \frac{32}{3} \pi^{2}$. It may be shown that when $a_{s}^{(2)} / a>1 / 4$ the Stokes second order profile exhibits a small secondary crest in the trough of the main wave.

This secondary crest does not appear in the periodic solution of the Korteweg-DeVries equation (Cnoidal waves), which is regarded as superior to the Stokes expansion in describing long finite amplitude waves. This argument leads us to limit the applicability of the theory developed to cases corresponding to values of $U_{r} \leq \frac{8}{3} \pi^{2}$.

\subsection{Cnoidal wave generation}

The free surface profile of a cnoidal wave, $\eta_{c}$, is mathematically represented as:

$$
\eta_{c}(x, t)=\left(h_{t}-h\right)+H c n^{2}\left(\theta_{c}, m\right)
$$

where

$$
\theta_{c}=2 K(m)\left(\frac{t}{T}-\frac{X_{c}}{L}\right)
$$

and $h_{t}$ is the distance between wave trough and bottom, $K(m)$ is the complete elliptic integral of the first kind, $c n$ is the Jacobian elliptic function and $m$ denotes the Jacobian elliptic parameter.

Using Newton's Rule Goring (1979) derived an iterative equation to calculate $\theta_{c}$. After determining iteratively $\theta_{c}$ for a specified time, the wave board displacement can be obtained as:

$$
X_{c}(t)=L\left(\frac{t}{T}-\frac{\theta_{c}}{2 K(m)}\right)
$$

Goring (1979) suggested to start the paddle movement from the point where paddle velocity is minimum to avoid spurious waves to be generated.

\subsection{Solitary wave generation}

The free surface profile of a solitary wave obtained as the solution of the weakly dispersive weakly nonlinear one-equation Boussinesq model (Boussinesq, 1871) is given by:

$$
\eta_{S}(x, t)=\operatorname{Hsech}^{2}(\theta)
$$

where

$$
\theta=k_{s}\left(C_{s} t-X_{S}\right) ; k_{s}=\sqrt{\frac{3 H}{4 h^{3}}} ; C_{s}=\sqrt{g(h+H)}
$$


Wavemaker theories for shallow water conditions are based on the assumption that paddle velocity should match desired water particle velocities. The time-dependent wave board trajectory can be obtained using Newton's Rule as suggested by Goring (1979) as:

$$
X_{S}(t)=\frac{H}{k_{s} h} \tanh k_{s}\left(C_{s} t-X_{S}\right)
$$

Although the simple $\operatorname{sech}^{2}$ profile given by Eq. (18) is not the solitary solution of the full Euler equation, it should represent a good approximation of it for low values of $H / h$ (Tanaka, 2006; Clamond and Dutykh, 2013; Dutykh and Clamond 2014). In other words, Eq. (18) can at best represent reference solitary wave solutions for low values of $H / h$ in the framework of inviscid Navier-Stokes equations. Tanaka (2006) and Clamond and Dutykh (2013) proposed methods and algorithms that permit computing higher solitary waves with improved accuracy. Goring (1979) proposed that an accurate solitary wave can be generated by Eq. (20) only if $H / h<0.2$.

\section{Physical Model Tests}

\subsection{Model Setup}

The experiments were carried out in the small scale flume CIEMito, of the Maritime Engineering Laboratory (LIM) at the Technical University of Catalonia BarcelonaTech (UPC-BarcelonaTech). The flume is $18 \mathrm{~m}$ long, $0.4 \mathrm{~m}$ wide, and $0.6 \mathrm{~m}$ deep and is provided with a piston type wave paddle capable of generating both regular and irregular waves. Thirty seven regular wave conditions were tested with wave height ranging between $0.03 \mathrm{~m}$ to 0.19 $\mathrm{m}$ and wave period from $1.60 \mathrm{~s}$ to $3.50 \mathrm{~s}$. Twenty four wave cases were tested with $0.32 \mathrm{~m}$ depth and thirteen with $0.25 \mathrm{~m}$ water depth. Ursell number $\left(\mathrm{U}_{\mathrm{r}}\right)$ ranged from 0.19 to 54.89 , and relative water depths from 0.06 to 0.82 (see Table 1). For each wave case the wavemaker motion was ramped up over a period of 2 wave periods after which a train consisting of ten periodic waves was generated followed by a ramp-down lasting 2 periods. The first wave ramp objective is to slowly increase the wavemaker stroke at startup until it reaches its desired value. Wave ramps avoid unwanted large waves considered as a transient response associated with the starting and stopping of the wavemaker (Madsen, 1970).

Paddle displacement was calculated by first order wavemaker theory as proposed by Biesel and Suquet (1951) (Eq. 8).

Water depth was kept constant along the flume and eight resistance gauges were used to measure the free surface evolution at $1.0 \mathrm{~m}, 2.0 \mathrm{~m}, 4.0 \mathrm{~m}, 4.5 \mathrm{~m}, 6.0 \mathrm{~m}, 7.0 \mathrm{~m}, 9.0 \mathrm{~m}$ and 10 $\mathrm{m}$ from the zero paddle position. A sampling rate of $100 \mathrm{~Hz}$ was used. The level of accuracy 
of these sensors is about $0.001 \mathrm{~m}$. The free surface sensors are represented in Fig. 1, and their relative positions can be obtained from Table 2.

Two dissipative zones composed of textile material were used in the experiments. In front of the paddle, $13.00 \mathrm{~m}$ away from it, a $2.50 \mathrm{~m}$ long dissipative zone was built. Behind the paddle, $0.75 \mathrm{~m}$ away from it, a $1.75 \mathrm{~m}$ long dissipative zone was used. During the experiments the gap between the sidewalls and the paddle was $0.01 \mathrm{~m}$ and the gap between the paddle and the bottom was $0.006 \mathrm{~m}$.

\subsection{Free and coupled harmonics analysis method}

In order to study the temporal and spatial evolution of the different harmonics present in the generated waves a particular methodology was developed. The main goal of this method is to analyze periodic waves from a given free surface series. Therefore, wave ramps, transition waves, reflected waves and waves previous to the arrival of free harmonics, should be eliminated from the free surface series. This methodology consists of three steps:

Step 1 - Determination of approximate number of waves that are periodic at a point $x \mathrm{~m}$ away from the paddle.

Considering $t_{1}$ the time of first harmonic $a$, and second coupled harmonic $a_{s}^{(2)}$, to travel a distance $x$ we have:

$$
t_{1}=\frac{x}{c_{g 0}}
$$

where $c_{g 0}$ is the wave group celerity calculated by means of linear wave theory:

$$
c_{g 0}=\frac{1}{2}\left[1+\frac{2 k_{0} h}{\sinh 2 k_{0} h}\right] \frac{g}{\omega} \tanh k_{0} h
$$

Considering $t_{2}$ the time of second free harmonic $a_{f}^{(2)}$ to travel the same distance $x$ we get:

$$
t_{2}=\frac{x}{c_{g f}}
$$

where $c_{g f}$ is the wave group celerity of the second free harmonic calculated by means of linear wave theory:

$$
c_{g f}=\frac{1}{2}\left[1+\frac{2 k_{f}^{(2)} h}{\sinh 2 k_{f}^{(2)} h}\right] \frac{g}{2 \omega} \tanh k_{f}^{(2)} h
$$

It can be noticed that $a$ and $a_{s}^{(2)}$ travel faster than $a_{f}^{(2)}$ which means $t_{2}>t_{1}$.

The time of last wave ramp arrival to $x$ is given by: 


$$
t_{3}=t_{1}+n_{i} T
$$

where $n_{i}$ is the number of wave ramps in the beginning of wave generation.

Thus we must consider the initial time of our free surface series as the time:

$$
t_{i}=t_{2}+n_{i} T
$$

Considering $t_{4}$ the time of last generated wave arrival at $x$ :

$$
t_{4}=t_{3}+n T+n_{f} T
$$

where $n$ is the number of generated waves and $n_{f}$ is the number of ramp waves at the end of paddle displacement.

Considering $t_{5}$ the time of first harmonic reflected by dissipation zone arrival at $x$ :

$$
t_{5}=\frac{(2 l-x)}{c_{g 0}}
$$

where $l$ is the distance from the mean paddle position and the dissipation zone. Consequently we consider the wave time series until the instant of time $t_{f}$, given by:

$$
t_{f}=\min \left[t_{4}, t_{5}\right]
$$

Since we have $t_{i}$ and $t_{f}$ the zero up crossing technique was used to quantify the number of purely progressive periodic waves $n_{p w}$.

Step 2 - Fourier series analysis of each wave determined in step 1.

Each of the $n_{p w}$ progressive wave determined in step 1 is analyzed by means of a Fast Fourier Transform (FFT).

Based on the principle of the FFT one data series can be described as the sum of sine waves:

$$
\eta=a_{1} \cos \omega_{1} t+b_{1} \sin \omega_{1} t+a_{2} \cos \omega_{2} t+b_{2} \sin \omega_{2} t+\cdots
$$

Considering $\omega_{2}=2 \omega_{1}$ Eq. (30) can be rewritten in the form:

$$
\eta=A_{1} \cos \left(\omega_{1} t-\varphi_{1}\right)+A_{2} \cos \left(2 \omega_{1} t-\varphi_{2}\right)+\cdots
$$

where amplitudes can be defined as:

$$
A_{1}=\sqrt{a_{1}{ }^{2}+b_{1}{ }^{2}} ; A_{2}=\sqrt{a_{2}^{2}+b_{2}{ }^{2}} ; \ldots
$$

and phases:

$$
\tan \varphi_{1}=\frac{b_{1}}{a_{1}} ; \tan \varphi_{2}=\frac{b_{2}}{a_{2}} ; \ldots
$$


Therefore it is possible to obtain amplitude and phase values for all the harmonics of each periodic regular wave that pass a wave sensor.

Step 3 - Comparison of the spatial evolution of periodic waves.

Once values of $A_{1}, A_{2}, \ldots$ and $\varphi_{1}, \varphi_{2} \ldots$ are obtained, as outlined in the previous step, it is possible to analyze their evolution along the flume comparing results of different wave sensors. If waves are perfectly of permanent form the amplitude of each harmonic should be constant along the flume. On the other hand variations of these values indicate the presence of free harmonics traveling with velocities different of the main and coupled harmonics. In a second order analysis the absence of free harmonic can be checked by the verification of the condition:

$$
2 \varphi_{1}-\varphi_{2}=0
$$

\subsection{Results}

For all the 37 cases the wave height generated was less than the target wave height and was not constant along the flume. Taking into account the mean of mean wave height along the flume the wave generated ranged between 0.71 and 0.93 times the desired wave height. In Fig. 2 the target wave height, real generated wave height and wave height predicted by Madsen (1970) formula (Eq. 9) are compared. From this figure, it can be seen that Madsen (1970) predicts for most of the tested cases the reduction in wave height due to the leakage between the paddle and the walls of the flume. However, for some cases, it can be observed that generated wave heights are slightly greater than those predicted by Madsen (1970). One reason for this difference can be due to possible wave reflection from the zone behind the paddle that is not taken into account in Madsen (1970) formula.

The wave periods of generated waves in the physical wave flume matched the target wave periods. In Table 3 really generated wave conditions in the physical flume are summarized. In this case, Ursell number ranged from 0.14 to 47.68 , and relative water depths from 0.06 to 0.82 (see table 3 ).

Four test cases were chosen from the 37 wave cases tested in order to be used as validation cases in the NWF. Table 4 summarizes the four chosen test cases and indicates wave heights prediction based on Madsen (1970) formulation for the four cases.

In Fig. 3 the amplitude of the five first harmonics are presented for the 4 test cases. Each column of points represents values obtained at one wave sensor. Wave sensors WG6 and WG7 were excluded from the analysis because they are close to the dissipation zone and in most of the cases no periodic waves were obtained. The amplitude values presented in Fig. 3 correspond to the mean values of all periodic waves registered at each wave sensor. 
As expected it can be seen from Fig. 3 that amplitude of the harmonics is not constant along the flume. The evolution of a2, a3, a4 and a5 along the flume is inverse of a1 evolution. The differences between the maximum and minimum value of the harmonic amplitudes registered along the flume increases with Ursell number (see Table 5). The value of variation of amplitude a2 ranges from $0.007 \mathrm{~m}$ (Case $\left.6 U_{r}=19.2\right)$ to $0.013 \mathrm{~m}$ (Case $37 U_{r}=48.3$ ). Also the relative phase of the first and second harmonic is not constant along the flume and the relation $2 \varphi_{1}-\varphi_{2}=0$ is not achieved (see Fig. 4). According to Madsen (1971) and Chapalain et al. (1992) these variations in amplitude and phase indicate the presence of free harmonics traveling with velocities different of the main and coupled harmonics. As a result, different types of variations in the wave profile can be observed such as: the crest is sharpened and the trough is flattened; a secondary crest is present in the trough of the main wave; steepening of the wave front (see Fig. 5 and 6).

\section{Numerical simulations}

\subsection{Sinusoidal Wave Generation}

Wave case 6, 3, 2 and 37 were also simulated in the NWF. To discretize the flume domain a grid mesh with constant nodal distance along the flume of $d x=d z=0.01 \mathrm{~m}$ was considered. This domain discretization leads to an initial finite elements mesh of 58862 nodes for simulations with $0.32 \mathrm{~m}$ water depth. The maximum time step used in the simulations was $0.001 \mathrm{~s}$. The numerical tests were run on a $2.67 \mathrm{GHz}$ Intel Core i7 CPU920. For these conditions, the numerical wave flume took about 139 hours to simulate $20 \mathrm{~s}$ of physical model test. Other time and mesh resolutions were tested in order to evaluate the computational time and the accuracy of the results along the flume. It was found that the accuracy of the free surface decreases substantially for nodal distances greater than $0.01 \mathrm{~m}$. In the numerical wave flume, waves were generated as similar as possible to those generated in the physical flume. A numerical piston paddle moving according to the physical piston paddle was reproduced. This boundary condition is solved by PFEM as a solid-liquid interaction problem. The numerical paddle displacement was calculated applying the wave height reduction model proposed by Madsen (1970) in order to take into account the leakage between the paddle and the walls of the physical flume. Generated wave height can be consulted in Table 4. The passive dissipation zone at the right end of the physical flume (see Fig. 1) was simulated in the numerical flume through the simulation of a fluid more viscous than water (Oliveira et al, 2009b).

Figures 5 and 6 plot the free surface evolution for case 3 and case 2 at four wave sensors from both experimental records and numerical simulations. Figure 5 indicates an excellent 
agreement between the numerical results and experimental data for both wave phase and wave height. A good agreement can be found in Fig. 6 for case 2. The variation in the wave form along the flume due to the presence of free harmonics is reproduced with accuracy by the NWF.

Figure 7 plots the amplitude of the first five harmonics along the NWF for wave case 6, 3, 2 and 37. Figure 8 plots the phase of the first five harmonics along the NWF for wave case 6,3 , 2 and 37. The evolution of the harmonics along the NWF fits quite well the experimental data. For cases 6 and 3 computations of free surface, amplitude and phase of harmonics are in perfect agreement with the experimental data (Fig. 3 and Fig. 4). For case 2 the wave generated in the NWF is slightly higher than in the experiments. Although the amplitude of the harmonics is slightly higher in the NWF its trend evolutions fit the physical results. For case 37 the amplitude of harmonics in Wave gauges WG0 and WG1 is slightly higher in the numerical flume.

\subsection{Second Order wave Generation}

Wave case 6, 3, 2 and 37 were simulated in the NWF using Madsen (1971) (Eq. 14) second order wavemaker theory to generate waves. The numerical features used in NWF were the same used in simulations presented in 5.1.

Figure 9 plots the amplitude of the first five harmonics along the flume for wave case 6, 3, 2 and 37. Figure 10 plots the phase of the first five harmonics along the flume for wave case 6 , 3,2 and 37.

For case 6 and case 3, both under the limits of application of Madsen (1971) theory $\left(h / L<O(0.1)\right.$ and $\left.U_{r}<26\right)$, free harmonics were practically eliminated. For these cases the amplitude of the first and second harmonic and wave form was kept constant along the flume. Although case 2 is out of the limits of application of Madsen (1971) wavemaker theory a good performance was obtained in the elimination of first and second free harmonics in this case. For wave case 37 also out of the limits of application of Madsen (1971) wavemaker theory the amplitude of free harmonics is highly but not totally reduced.

\subsection{Cnoidal Wave Generation}

Wave case 6, 3, 2 and 37 were simulated in the NWF using Goring (1979) wavemaker theory based on cnoidal wave theory (Eq. 17). The numerical features used in NWF were the same used in simulations presented in 5.1 and 5.2.

Figure 11 plots the amplitude of the first five harmonics along the flume for wave case 6, 3, 2 and 37. Figure 12 plots the phase of the first five harmonics along the flume for wave case 6 , 
3, 2 and 37. Figure 13 and 14 compares the free surface obtained in the NWF with sinusoidal, second order and cnoidal generations for case 3 and 2 , respectively.

The differences between the maximum and minimum value of the harmonic amplitudes obtained in the NWF with the three different wavemaker theories can be found in Table 6.

The improvements in keeping the wave form constant along the flume using the wavemaker theory based on cnoidal wave theory are of the same order of magnitude of those obtained with second order wavemaker theory. However for the four cases simulated the performance of the second order wavemaker theory was better than that obtained in the cnoidal wavemaker theory.

A theoretical wave case CN01 of $H=0.10 \mathrm{~m}, T=3.0 \mathrm{~s}$ and $h=0.25 \mathrm{~m}\left(h / L=0.05\right.$ and $U_{r}=$ 136) was simulated in the NWF. For these extreme long wave conditions second order wavemaker theory by Madsen (1971) can't be applied $\left(U_{r}<26\right)$. If we try to obtain the paddle displacement with Madsen (1971) theory the amplitude of the second term of Eq. (14) is very high and a second crest can be detected in the obtained paddle displacement.

Figure 15 compares the free surface obtained at four points of the NWF with the theoretical free surface given by cnoidal wave theory. Figure 16 shows the variation of harmonic amplitude and phase along the NWF. From Fig. 15 and 16 it can be observed that the wave keeps its form and the amplitude of the harmonics along the flume. Further, its shape agrees quite well with cnoidal wave theory. However, small numerical perturbations are introduced in the free surface at the troughs.

\subsection{Solitary Wave Generation}

A solitary wave case $\mathrm{S} 01$ of $H=0.045 \mathrm{~m}$ and $h=0.25 \mathrm{~m}(H / h=0.18)$ was simulated in the NWF using the solitary wave generation theory proposed by Goring (1979) (eq. 20). The numerical features used in NWF were the same used in simulations presented in 5.1, 5.2 and 5.3. According to Goring (1979) for this solitary wave condition the paddle displacement is $0.24 \mathrm{~m}$, the maximum paddle velocity is $0.25 \mathrm{~m} / \mathrm{s}$ and the duration time of the paddle displacement is $3.18 \mathrm{~s}$. Figure 17 compares the free surface evolution obtained in the NWF with the free surface given by the Boussinesq-type solution for a solitary wave (eq. 18). From this figure it can be seen that, in general, the numerical wave form agrees quite well with the Boussinesq-type solution. However, small differences in the free surface can be noticed close to the wave crest. The ratio between desired and generated wave height decreases from 0.985 to 0.971 between WG0 and WG5. 


\section{Conclusions}

In this paper, we describe for the first time the implementation and the validation of regular long wave generation in a NWF based on the PFEM. Three types of waves were generated based on Stokes second order wave theory, cnoidal wave theory and solitary wave theory through a piston type paddle boundary condition. Practically, this allows the simulation of a variety of intermediate and shallow water wave conditions commonly used in coastal hydraulic studies.

We studied the nonlinear phenomena that occur when regular long waves are generated in a NWF based on the PFEM by a sinusoidal wavemaker movement. Long wave physical experiments based on a sinusoidal paddle movement have been conducted. We show that the evolution of the harmonics (coupled and free) along the NWF fits quite well the experimental data. Generally speaking, these results indicate that as it happens in physical flumes, a sinusoidal wavemaker theory is not directly suitable to generate long waves in a NWF based on PFEM.

The second order wavemaker theory developed by Madsen (1971) was implemented in the NWF. Free harmonics were eliminated for wave cases under the limits of application of Madsen (1971) theory $\left(h / L<O(0.1)\right.$ and $\left.U_{r}<26\right)$. For a wave case $h / L=0.1$ and $U_{r}=35.0$ good performance was obtained with the elimination of the first and second free harmonics. However for $h / L=0.06$ and $U_{r}=42.6$ the amplitude of free harmonics is reduced but not totally removed.

The cnoidal wavemaker theory presented by Goring (1979) was implemented in the NWF. The improvements in keeping the desired wave form along the flume using cnoidal theory are of the same order of magnitude as those obtained with second order wavemaker theory (for $U_{r} \leq 42.6$ ). A theoretical wave case of $h / L=0.05$ and $U_{r}=136$ was simulated in the NWF. It was observed that the wave keeps its form and the amplitude of the harmonics along the flume. Further the resulting shape agrees quite well with cnoidal wave theory. The ability to generate solitary waves of $H / h<0.2$ was implemented in the NWF based on the wavemaker theory proposed by Goring (1979). For a solitary wave of $H / h=0.18$ generated in the NWF, the wave form agrees quite well with the Boussinesq-type solution for a solitary wave. However, small differences were observed close to the wave crest.

The ability of the PFEM to simulate complex solid-fluid interaction problems and fast free surface changes allow the implementation of wavemaker theories dealing with fast paddle displacements. The implementation of other wavemaker theories for the generation of solitary waves in the NWF is currently being carried out. This implementation is expected to provide a more realistic representation of high amplitude solitary waves than the Boussinesq-type solution implemented in this work. 
For practical coastal hydraulic applications a compromise has to be made between the accuracy and validity field of each wavemaker theory implemented in the NWF. Further work should aim to implement and validate the generation of irregular waves in the NWF.

\section{Acknowledgements}

The authors wish to thank UPC-BarcelonaTech/CIEM lab team members for their help in undertaking model tests. We are grateful to the reviewers of this paper for critical evaluation and valuable suggestions. The first author gratefully acknowledges the Post doctoral scholarship provided by "Coordenação de Aperfeiçoamento de Pessoal de Nível Superior" (CAPES), contract number A039_2013. The second author acknowledges the support of the PLAN WAVE project (nº CTM2013-45141-R).

\section{Notation}

a wave amplitude

$a_{f}^{(2)} \quad$ second harmonic free wave

$a_{s}^{(2)} \quad$ second harmonic coupled with the first harmonic

$b \quad$ width of the wave tank

$c_{g f} \quad$ wave group celerity of the second free harmonic

$c_{g 0} \quad$ wave group celerity

cn Jacobian elliptic function

$f_{i} \quad$ source tensor

$g$ gravity

$h \quad$ water depth

$h_{t} \quad$ distance between wave trough and bottom

$H \quad$ wave height

$k_{0} \quad$ wave number

$k_{f}^{(2)} \quad$ wave number of second harmonic free wave

$K(m)$ complete elliptic integral of the first kind

$l \quad$ distance from the mean paddle position and the dissipation zone

$L \quad$ wave length

$m \quad$ Jacobian elliptic parameter

$n \quad$ number of generated waves

$n_{i} \quad$ number of wave ramps in the beginning of wave generation

$n_{f} \quad$ number of ramp waves at the end of wave generation

$n_{p w} \quad$ number of purely progressive periodic waves 
$p \quad$ the pressure

$u_{i} \quad$ cartesian components of the velocity field

$U \quad$ amplitude of the sinusoidal wavemaker velocity

$U_{r} \quad$ Ursell number

$t \quad$ time

$t_{i} \quad$ initial time of free surface series

$t_{f} \quad$ final time of free surface series

$t_{1}$ time of first harmonic to travel a certain distance

$t_{2}$ time of second free harmonic to travel certain distance

$t_{3} \quad$ time of last wave ramp arrival to a certain distance

$t_{4} \quad$ time of last generated wave arrival to a certain distance

$t_{5}$ time of first harmonic reflected by dissipation zone arrival to a certain distance

$T \quad$ wave period

$x \quad$ space position

$X_{0} \quad$ paddle position given by first order wavemaker theory

$X_{2} \quad$ paddle position given by second order wavemaker theory

$X_{c} \quad$ paddle position given by cnoidal wavemaker theory

$X_{S} \quad$ paddle position given by solitary wavemaker theory

$\Delta_{B} \quad$ gap between the wavemaker and the bottom

$\Delta_{S} \quad$ gap between the sidewalls and the wavemaker

$\eta \quad$ free surface

$\eta^{(1)} \quad$ free surface of first harmonic linear wave

$\eta_{c} \quad$ free surface of a cnoidal wave

$\eta_{f}^{(2)} \quad$ free surface of second harmonic free wave

$\eta_{S} \quad$ free surface of a solitary wave

$\eta_{s}^{(2)} \quad$ free surface of second harmonic coupled with the first harmonic

$\mu \quad$ viscosity

$\rho \quad$ density

$\tau_{i j} \quad$ deviatoric stress tensor

$\omega \quad$ angular frequency

\section{References}

Biésel, F., Suquet, F. (1951). Les appareils générateurs de houle en laboratoire. La Houille Blanche 6 (2, 4 \& 5). 
Becker, P., Idelsohn, S.R., Oñate, E. (2015). A unified monolithic approach for multi-fluid flows and fluid-structure interaction using the Particle Finite Element Method with fixed mesh. Comput. Mech. 55, 1091-1104.

Boussinesq J.V. (1871) Théorie de l'intumescence liquide, appelée onde solitaire ou de translation, se propageant dans un canal rectangulaire. C. R. Acad. Sci. Paris, Vol. 72, pp 755-759

Chapalain G., Cointe R., Temperville A. (1992). Observed and modeled resonantly interacting progressive water-waves. Coast. Eng. 16, 267-300.

Chen Y.Y., Kharif C., Yang J.H., Hsu H.C., Touboul J., Chambarel J. (2015). An experimental study of steep solitary wave reflection at a vertical wall. Eur. J. Mech. BFluid, 49, 20-28.

Clamond D., Dutykh D. (2013) Fast accurate computation of the fully non linear solitary surface gravity waves. Comput Fluids 84, 35-38.

Codina, R. (2001). Pressure Stability in Fractional Step Finite Element Methods for Incompressible Flows. J. Comput. Phys. 170, 112-140.

Dalrymple, R. A., Rogers, B. D. (2006). Numerical modeling of water waves with the SPH method. Coast. Eng. 53, 141-147.

Dang, T.S., Meschke, G. (2014). An ALE-PFEM method for the numerical simulation of two-phase mixture flow. Comput. Methods Appl. Mech. Eng. 278, 599-620.

Daugaard, E. (1972). Generation of Regular Waves in the Laboratory. Doctoral Thesis, Institute of Hydrodynamics and Hydraulic Engineering, Technical University of Denmark.

Domínguez J.M, Crespo A.J.C, Rogers B.D, Gómez-Gesteira M. (2013). New multi-GPU implementation for Smoothed Particle Hydrodynamics on heterogeneous clusters. Comput. Phys. Commun. 184, 1848-1860.

Dutykh D., Clamond D. (2014) Efficient computation of steady solitary gravity waves. Wave Motion, 51, 86-99.

Edelsbrunner, H., Mucke, E. P. (1994). Three-dimensional alpha-shape. ACM Trans. Graph. 3, 43-72.

Flick, R. E., Guza, R. T. (1980). Paddle Generated Waves in Laboratory Channels. J. Waterw. Port Coast. Ocean Eng. 106, 79-97.

Fontanet, P. (1961). Théorie de la génération de la houle cylindrique per un batteur plan. Houille Blanche 16, 3-31.

Galvin, C. J. (1968). Shapes of Unbroken Periodic Gravity Water Waves. Eos, Trans. Amer. Geophys. Union 49, 206.

Gimenez, J.M., González, L.M. (2015). An extended validation of the last generation of particle finite element method for free surface flows. J. Comput. Phys. 284, 186-205. 
Goda, Y. (1997). Recurring Evolution of Water Waves Through Nonresonant Interactions. Proc. Int. Conf. 3rd International Symposium on Ocean Wave Measurements and Analysis, Virginia Beach, 1-23.

Goda, Y. (1967). Travelling Secondary Wave Crest in Wave Channels. Apendix to: Laboratory Investigation on Wave Transmition Over Breakwaters. Rep. No. 13, Port \& Harbour Research Institute, Japan.

Gomez-Gesteira, M., Crespo, A.J.C. Rogers, B.D., Dalrymple, R.A., Dominguez, J.M., Barreiro, A. (2012). SPHysics - development of a free-surface fluid solver - Part 2: Efficiency and test cases. Comput \& Geosci 48, 300-307.

Goring, D. G. (1979). Tsunamis - The propagation of Long Waves Onto a Shelf. Doctoral Thesis, W. M. Keck Laboratory of Hydraulics and Water Resources, California Institute of Technology, Pasadena, California.

Grilli S.T., Svendsen I.A. (1991). The propagation and runup of solitary waves on steep slopes, Rep. No.91-4, Center for Applied. Coastal Research, Univ. of Delaware, Newark (DE, USA).

Grilli S.T., Subramanya R., Svendsen I.A., Veeramony J. (1994). Shoaling of solitary waves on plane beaches. J. Waterw. Port Coast. Ocean Eng. 120, 609-628.

Guizien K., Barthélémy E. (2002). Accuracy of solitary wave generation by a piston wave maker, J. Hydraulic Res. 40, 321-331.

Herault, A., Bilotta G., Dalrymple R. A. (2010). SPH on GPU with CUDA. J. Hydraulic Res. 48(Extra Issue), 74-79.

Hori, C., Gotoh, H., Ikari, H. Khayyer, A. (2011). GPU-acceleration for Moving Particle Semi-Implicit method. Comput Fluids 51, 174-183.

Hudspeth, R. T., Sulisz, W. (1991). Stokes drift in two-dimensional wave flumes. J. Fluid Mech. 230, 209-229.

Hughes, S. A. (1993). Physical Models and Laboratory Techniques in Coastal Engineering, vol. 7 of Advanced Series on Ocean Engineering, World Scientific.

Idelsohn, S. R., Calvo, N., Oñate, E. (2003a). Polyhedrization of an arbitrary 3D point set. Comput. Method. Appl. M. 192, 2649-2667.

Idelsohn, S. R., Oñate, E., Calvo, N., Pin, F. D. (2003b). The meshless finite element method. Int. J. Numer. Meth. Eng. 58, 893-912.

Idelsohn, S. R., Oñate, E., Pin, F. D., Calvo, N. (2006). Fluid-structure interaction using the particle finite element method. Comput. Method. Appl. M. 195, 2100-2123.

Iwagaki, Y., Sakai, T. (1970). Horizontal Water Particle Velocity of Finite Amplitude Waves. Proc. Int. Conf. on Coastal Engineering, ASCE, 309-325. 
Khayyer, A., Gotoh, H. (2009). Modified Moving Particle Semi-implicit methods for the prediction of 2D wave impact pressure. Coast. Eng. 56, 419-440.

Hudspeth, R. T., Guenther, R. B. (2009). Wavemakers Theories. Handbook of coastal and ocean engineering. World Scientific.

Koshizuka, S., Nobe, A. Oka, Y. (1998). Numerical analysis of breaking waves using the moving particle semi-implicit method. Int. J. Numer. Meth. Fl. 26, 751-769.

Lara, J. L., Garcia, N., Losada, I. J. (2006). RANS modelling applied to random wave interaction with submerged permeable structures. Coast. Eng. 53, 395-417.

Larese, A., Rossi, R., Oñate, E., Idelsohn, S.R. (2012). A coupled PFEM-Eulerian approach for the solution of porous FSI problems. Comput. Mech. 50, 805-819.

Le Méhauté, B., Divoky, D., Lin, A. (1968). Shallow Water Waves: A Comparison of Theories and Experiments. Proc. Int. Conf. on Coastal Engineering, ASCE, 86-107.

Lin, P. Z., Liu, P. L. (1998). A numerical study of breaking waves in the surf zone. J. Fluid Mech. 359, 359239.

Liu P.L.-F., Simarro G., Vandever J., Orfila A. (2006). Experimental and numerical investigation of viscous effects on solitary wave propagation in a wave tank. Coast. Eng. 53, $181-190$.

Madsen, O. S. (1971). On the Generation of long Waves. J. Geophys. Res. 76, 8672-8683.

Madsen, O. S. (1970). Wave generated by piston-type wavemaker. Proc. Int. Conf. on Coastal Engineering, ASCE, Washington, 589-607.

Malek-Mohammadi S., Testik F.Y. (2010). New methodology for laboratory generation of solitary waves. J. Waterw. Port Coast. Ocean Eng.136, 286-294.

Maza M., Lara, J. L., Losada, I. (2013). A coupled model of submerged vegetation under oscillatory flow using Navier-Stokes equations, Coast. Eng. 80, 16-34.

Monaghan, J. J., Kos, A. (1999). Solitary Waves on a Cretan Beach. J. Waterw. Port Coast. Ocean Eng. 125, 145-155.

Morison, J. R., Crooke, R. C. (1953). The Mechanics of Deep Water, Shallow Water and Breaking Waves: Beach Erosion Board. Tech. Memo No. 40, Washington DC.

Oliveira, T.C.A., Sánchez-Arcilla, A., Gironella, F. X. (2012). Simulation of Wave Overtopping of Maritime Structures in a Numerical Wave Flume. J. Appl. Math. 2012, Article ID 246146, 19 pages.

Oliveira, T.C.A., Gironella, F.X., Sanchez-Arcilla, A., Sierra, J. P., Celigueta, M.A. (2009a). Nonlinear regular wave generation in numerical and physical flumes. J. Coast. Res. 56, 1025-1029.

Oliveira, T.C.A., Celigueta, M. A., Gironella, F.X., Sánchez-Arcilla, A. Oñate, E. (2009b). Absorption of water waves in a two-dimensional numerical flume Proc. Int. Conf. Computational Methods in Marine Engineering III, Barcelona, 105-108. 
Oñate, E. (2000). A stabilized finite element method for incompressible viscous flows using a finite increment calculus formulation. Comput. Method. Appl. M. 182, 355-370.

Oñate, E., Del Pin, F., Aubry, R. (2004). The Particle Finite Element Method. An overview. Int. J. Comput. Methods 1, 267-307.

Oñate, E., Idelsohn, S. R., Celigueta, M. A., Rossi, R. (2008). Advances in the particle finite element method for the analysis of fluid-multibody interaction and bed erosion in free surface flows. Comput. Method. Appl. M. 197, 1777-1800.

Rossi, R., Oñate, E. (2010). Analysis of some partitioned algorithms for fluid-structure interaction. Eng. Comput. 27, 20-56.

Schäffer, H. A. (1996). Second-order wavemaker theory for irregular waves. Ocean Eng. 23, 47-88.

Schäffer H.A., Steenberg C. (2003). Second-order wavemaker theory for multidirectional waves. Ocean Eng., 30, 1203-1231.

Shao, S., Ji, C., Graham, D. I., Reeve, D. E., James, P. W., Chadwick, A. J. (2006). Simulation of wave overtopping by an incompressible SPH model. Coast. Eng. 53, 723-735.

Steenberg C., Schäffer H.A. (2001). Second-order wave generation in laboratory basins. Proc. Int. Conf. on Coastal Engineering, ASCE, 994-1007.

Synolakis C. (1990). Generation of long waves in laboratory. J. Waterw. Port Coast. Ocean Eng. 116(2), 252-266.

Tanaka M. (1986) The stability of solitary waves. Phys. of Fluids 29, 650-655.

van Gent, M. R. A., Tönjes, P., Petit, H. A. H., van den Bosch, P. (1994). Wave action on and in permeable structures. Proc. Int. Conf. on Coastal Engineering, ASCE, Kobe, Japan, 1739-1753.

Van Gent, M. R. A. (1994). The modelling of wave action on and in coastal structures. Coast. Eng. 22, 311-339.

Wu N.-J., Tsay T.-K., Chen Y.-Y. (2014). Generation of stable solitary waves by a pistontype wavemaker. Wave Motion, 51, 240-255.

Zhang, H., Schäffer, H. A. (2007). Approximate Stream Function wavemaker theory for highly non-linear waves in wave flumes. Ocean Eng. 34, 1290-1302. 
Table 1 - Summary of planned test wave conditions.

\begin{tabular}{lllll}
\hline $\mathrm{h}(\mathrm{m})$ & $\mathrm{H}(\mathrm{m})$ & $\mathrm{T}(\mathrm{s})$ & $\mathrm{Ur}$ & $\mathrm{h} / \mathrm{L}$ \\
\hline 0.32 & {$[0.030,0.160]$} & {$[0.5,2.0]$} & {$[0.19,54.89]$} & {$[0.10,0.82]$} \\
0.25 & {$[0.025,0.120]$} & {$[1.0,1.7]$} & {$[2.72,48.28]$} & {$[0.06,0.16]$} \\
\hline
\end{tabular}


Table 2 - Free surface sensor positions.

\begin{tabular}{lll}
\hline Sensor & $\begin{array}{l}\text { Wavemaker } \\
\text { distance }(\mathrm{m})\end{array}$ & $\begin{array}{l}\text { Dissipation zone } \\
\text { distance }(\mathrm{m})\end{array}$ \\
\hline WG0 & 1.0 & 12.0 \\
WG1 & 2.0 & 11.0 \\
WG2 & 4.0 & 9.0 \\
WG3 & 4.5 & 8.5 \\
WG4 & 6.0 & 7.0 \\
WG5 & 7.0 & 6.0 \\
WG6 & 9.0 & 4.0 \\
WG7 & 10.0 & 3.0 \\
\hline
\end{tabular}

1

2

3

4

5

6

10

11

12

13

14

15

16

17

18

19

20

21

22

23

24

25

26

27

28

29

30

31

32

33

34

35

36

37

38

39

40

41

42

43

44

45

46

47

48

49

50

51

52

53

54

55

56

57

58

59

60

URL: http://mc.manuscriptcentral.com/jhr 
Table 3 - Summary of waves conditions generated in the physical flume.

\begin{tabular}{lllll}
\hline $\mathrm{h}(\mathrm{m})$ & $\mathrm{H}(\mathrm{m})$ & $\mathrm{T}(\mathrm{s})$ & $\mathrm{Ur}$ & $\mathrm{h} / \mathrm{L}$ \\
\hline 0.32 & {$[0.021,0.140]$} & {$[0.5,2.0]$} & {$[0.14,47.68]$} & {$[0.10,0.82]$} \\
0.25 & {$[0.019,0.112]$} & {$[1.0,1.7]$} & {$[2.39,45.06]$} & {$[0.06,0.16]$} \\
\hline
\end{tabular}


Table 4 - Wave conditions in the physical flume for the four selected test cases.

\begin{tabular}{llllllll}
\hline \multicolumn{3}{l}{ Theoretical conditions } & & & \multicolumn{3}{c}{$\begin{array}{l}\text { Based on Madsen } \\
(1970)\end{array}$} \\
\hline Case & $\mathrm{h}(\mathrm{m})$ & $\mathrm{H}(\mathrm{m})$ & $\mathrm{T}(\mathrm{s})$ & $\mathrm{Ur}$ & $\mathrm{h} / \mathrm{L}$ & $\mathrm{H}(\mathrm{m})$ & $\mathrm{Ur}$ \\
\hline 6 & 0.32 & 0.10 & 1.70 & 23.71 & 0.11 & 0.084 & 19.20 \\
3 & 0.32 & 0.10 & 1.90 & 30.58 & 0.10 & 0.083 & 25.38 \\
2 & 0.32 & 0.12 & 2.0 & 41,16 & 0.10 & 0.102 & 34.99 \\
37 & 0.25 & 0.12 & 1.70 & 48.28 & 0.06 & 0.106 & 42.64 \\
\hline
\end{tabular}


Table 5 - Differences between the maximum and minimum value of harmonic amplitudes registered along the physical flume (values in $\mathrm{mm}$ ). Last line corresponds to the maximum of the absolute values obtained for $2 \varphi_{1}-\varphi_{2}$ (values in rad).

\begin{tabular}{lllll}
\hline & Case 6 & Case 3 & Case 2 & Case 37 \\
\hline a1 & 3 & 4 & 6 & 8 \\
a2 & 7 & 7 & 11 & 13 \\
a3 & 3 & 2 & 5 & 8 \\
a4 & ---- & ---- & 2 & 5 \\
a5 & --- & --- & --- & 3 \\
$2 \varphi_{1}-\varphi_{2}$ & 0.59 & 0.55 & 0.55 & 0.80 \\
\hline
\end{tabular}


Table 6 - Differences between the maximum and minimum value of harmonic amplitudes registered along the NWF with first order (Sin) second order (2nd) and cnoidal (cno) wave based wavemaker theories (values in mm). Last line corresponds to the maximum of the absolute values obtained by $2 \varphi_{1}-\varphi_{2}$ along the NWF (values in rad).

\begin{tabular}{lllllllllllll}
\hline & \multicolumn{3}{c}{ Case } & $(\mathrm{Ur}=19.2)$ & \multicolumn{3}{c}{ Case 3 } & $(\mathrm{Ur}=25.4)$ & \multicolumn{3}{c}{ Case $2(\mathrm{Ur}=35.0)$} & \multicolumn{3}{c}{ Case 37 $(\mathrm{Ur}=42.6)$} \\
& Sin & 2nd & Cno & Sin & 2nd & Cno & Sin & 2nd & Cno & Sin & 2nd & Cno \\
\hline a1 & 4 & 1 & 1 & 4 & 1 & 1 & 9 & 2 & 3 & 11 & 3 & 5 \\
a2 & 8 & 1 & 3 & 9 & 2 & 3 & 15 & 2 & 5 & 16 & 5 & 6 \\
a3 & 3 & 1 & 1 & 4 & 1 & 1 & 7 & 3 & 3 & 11 & 3 & 4 \\
a4 & ---- & ---- & ---- & ---- & ---- & ---- & 4 & 2 & 1 & 7 & 3 & 2 \\
a5 & ---- & ---- & --- & ---- & --- & --- & ---- & --- & -- & 6 & 1 & 2 \\
$2 \varphi_{1}-\varphi_{2}$ & 0.73 & 0.10 & 0.23 & 0.84 & 0.13 & 0.17 & 0.86 & 0.12 & 0.18 & 0.87 & 0.21 & 0.35 \\
\hline
\end{tabular}


1

2

3

4

5

6

7

8

9

10

11

12

13

14

15

16

17

18

19

20

21

22

23

24

25

26

27

28

29

30

31

32

33

34

35

36

37

38

39

40

41

42

43

44

45

46

47

48

49

50

51

52

53

54

55

56

57

58

59

60

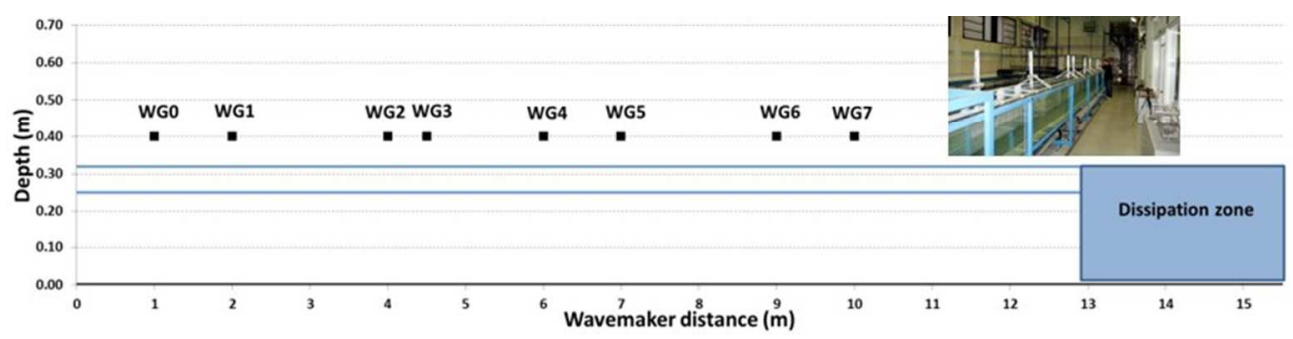

Figure 1 - Sketch of CIEMito wave flume used to reproduce and understand the generation of regular long waves.

$148 \times 36 \mathrm{~mm}(150 \times 150 \mathrm{DPI})$ 
Figure 2 - Comparison between desired wave height, real generated wave height and wave height predicted by Madsen (1970) formula.

$$
135 \times 52 \mathrm{~mm}(150 \times 150 \mathrm{DPI})
$$

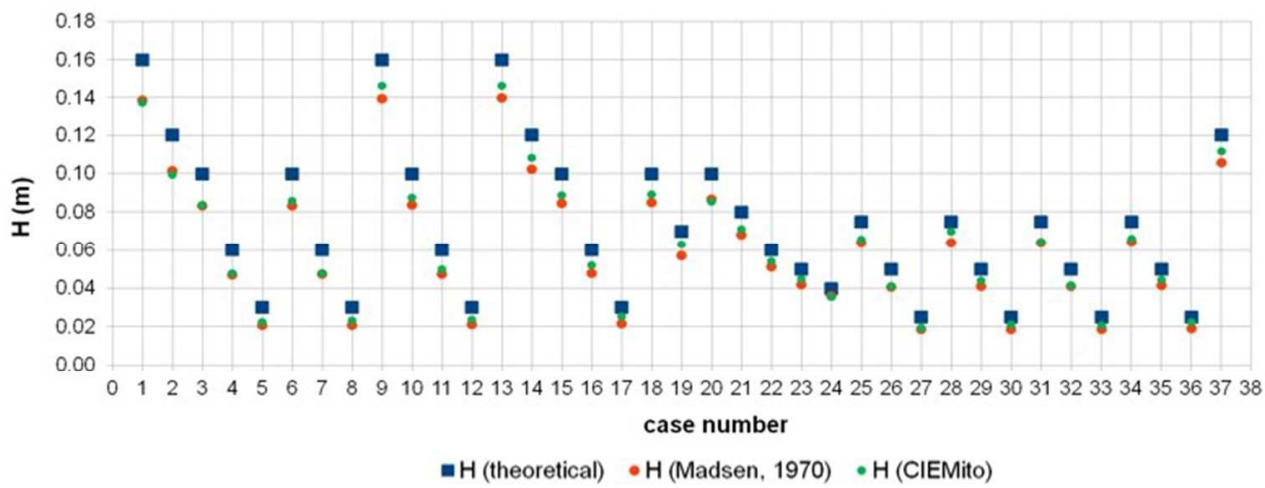



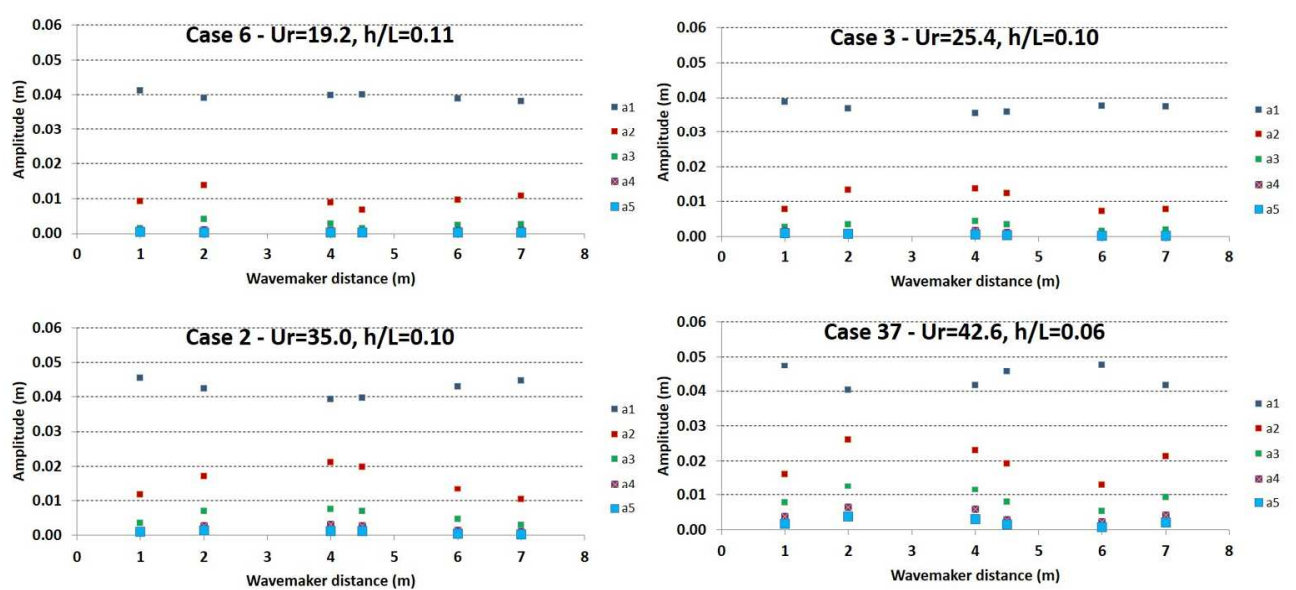

Figure 3 - Amplitude of five first harmonics along the physical flume. Wave generated with sinusoidal wavemaker motion.

$334 \times 153 \mathrm{~mm}$ ( $150 \times 150$ DPI) 
Figure 4 - Phase of two first harmonics along the physical flume. Wave generated with sinusoidal wavemaker motion.

$335 \times 152 \mathrm{~mm}(150 \times 150 \mathrm{DPI})$ 

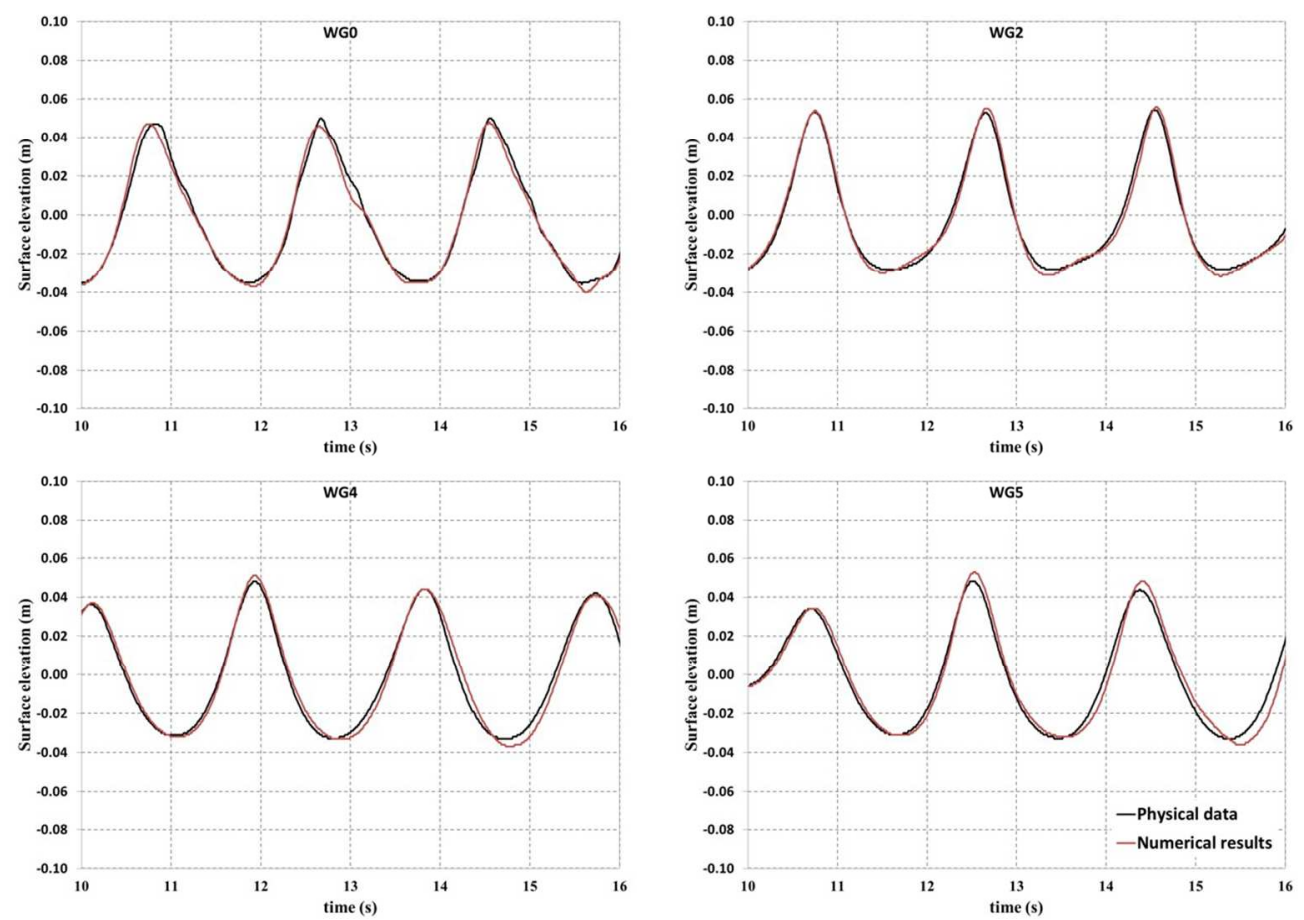

Figure 5 - Numerical and physical free surface comparison at four different locations, all of them corresponding to wave case 3 defined by $U r=19.2$ and $h / L=0.11$.

$215 \times 152 \mathrm{~mm}(150 \times 150 \mathrm{DPI})$ 

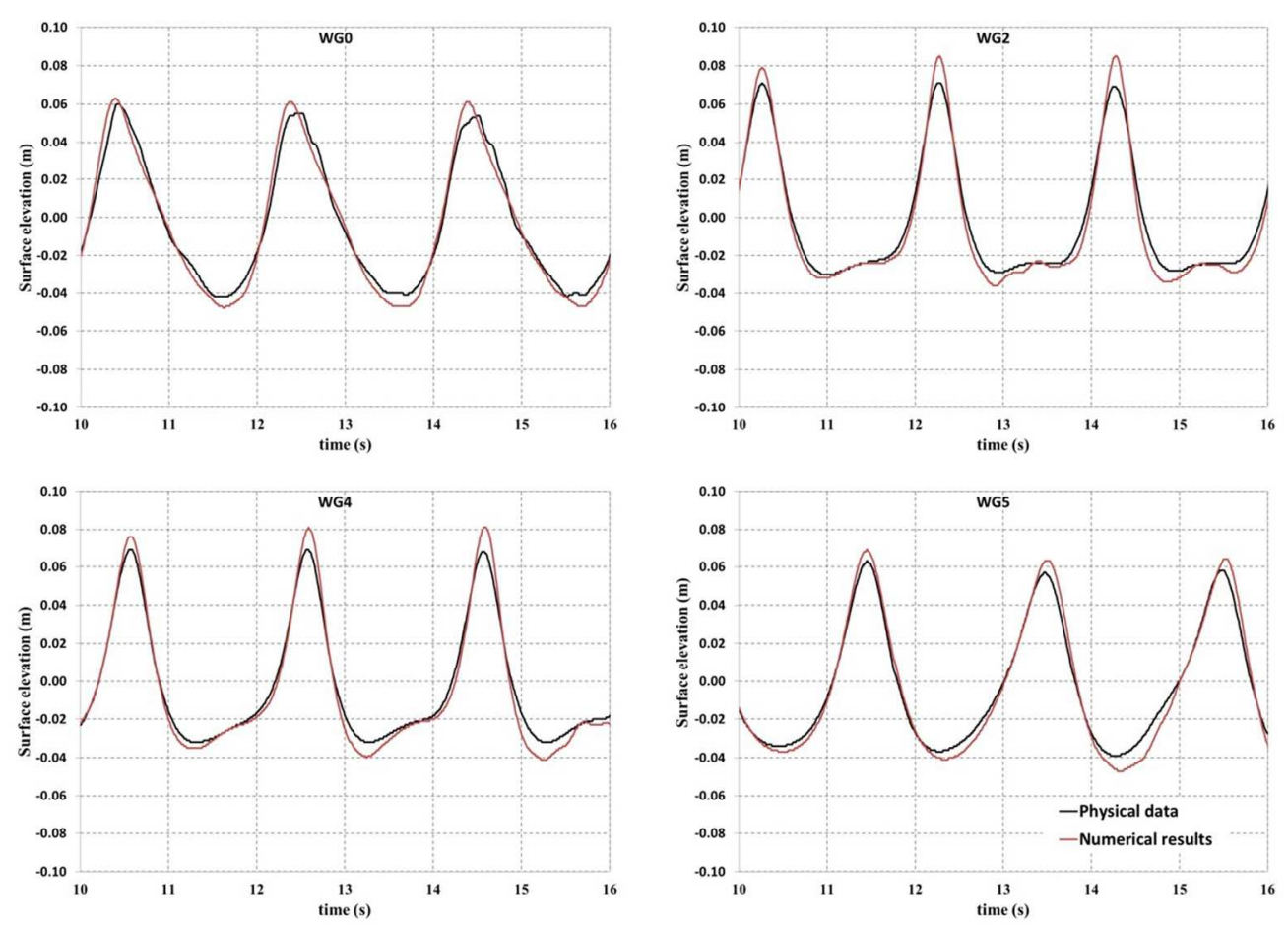

Figure 6 - Numerical and physical free surface comparison at four different locations, all of them corresponding to wave case 2 defined by $\mathrm{Ur}=41.2$ and $\mathrm{h} / \mathrm{L}=0.10$.

$215 \times 154 \mathrm{~mm}(150 \times 150 \mathrm{DPI})$ 

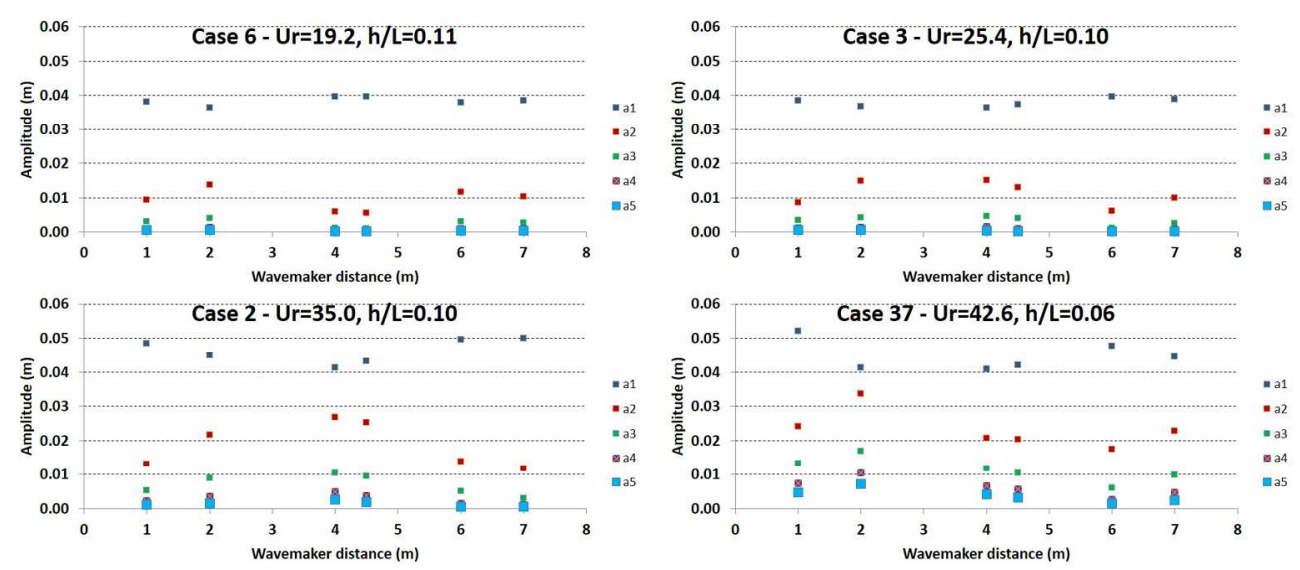

Figure 7 - Amplitude of five first harmonics along the numerical wave flume. Wave generated with sinusoidal wavemaker motion. $338 \times 148 \mathrm{~mm}(150 \times 150$ DPI $)$ 
Figure 8 - Phase of five first harmonics along the numerical wave flume. Wave generated with sinusoidal wavemaker motion.

$$
334 \times 152 \mathrm{~mm}(150 \times 150 \mathrm{DPI})
$$



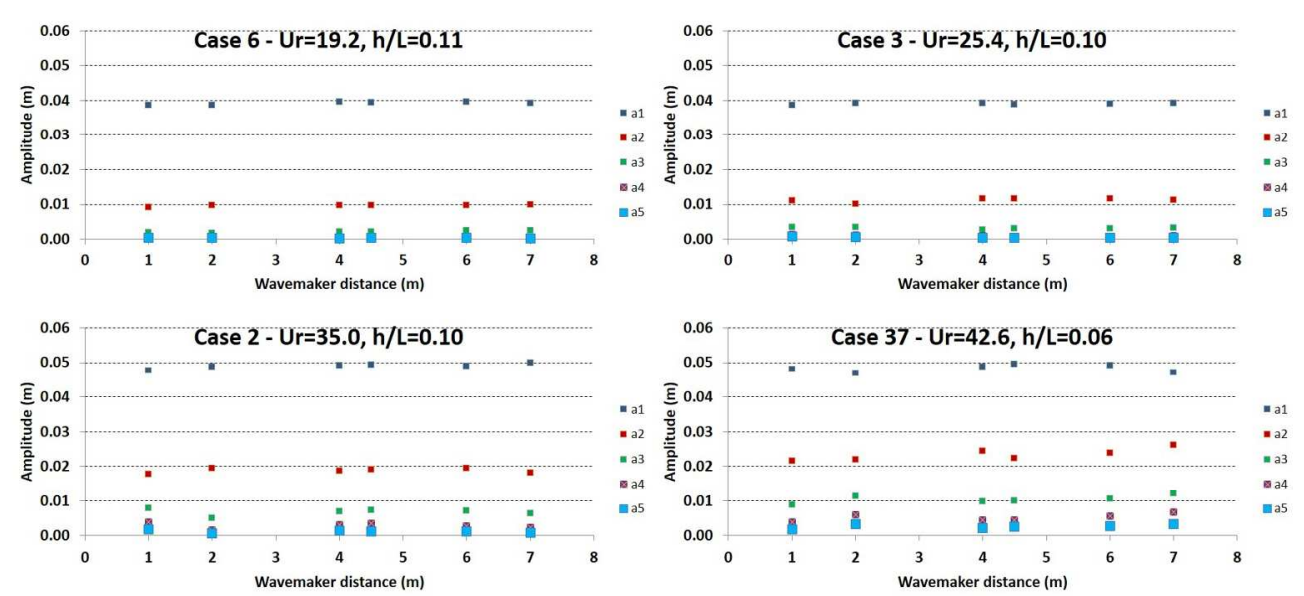

Figure 9 - Amplitude of five first harmonics along the numerical wave flume. Wave generated with second order wavemaker theory.

$$
333 \times 152 \mathrm{~mm}(150 \times 150 \mathrm{DPI})
$$


Figure 10 - Phase of five first harmonics along the numerical wave flume. Wave generated with second order wavemaker theory.

$$
332 \times 152 \mathrm{~mm}(150 \times 150 \mathrm{DPI})
$$



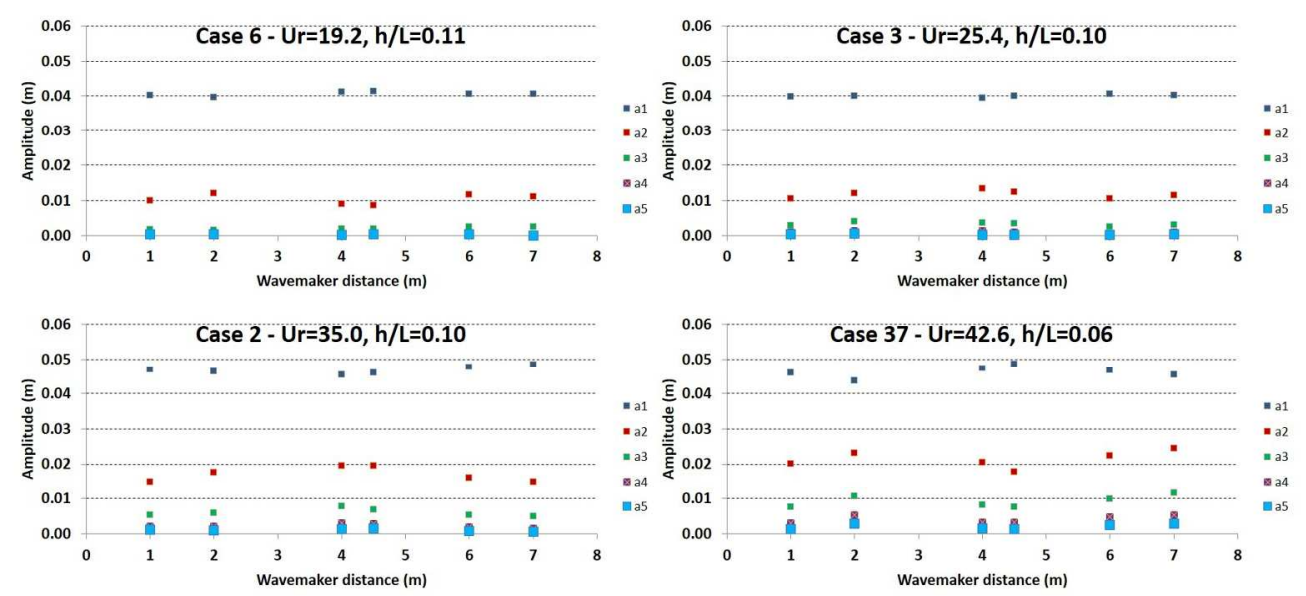

Figure 11 - Amplitude of five first harmonics along the numerical wave flume. Wave generated with a wavemaker theory based on cnoidal wave theory.

$$
332 \times 152 \mathrm{~mm}(150 \times 150 \mathrm{DPI})
$$


Figure 12 - Phase of five first harmonics along the numerical wave flume. Wave generated with a wavemaker theory based on cnoidal wave theory.

$$
332 \times 152 \mathrm{~mm}(150 \times 150 \mathrm{DPI})
$$



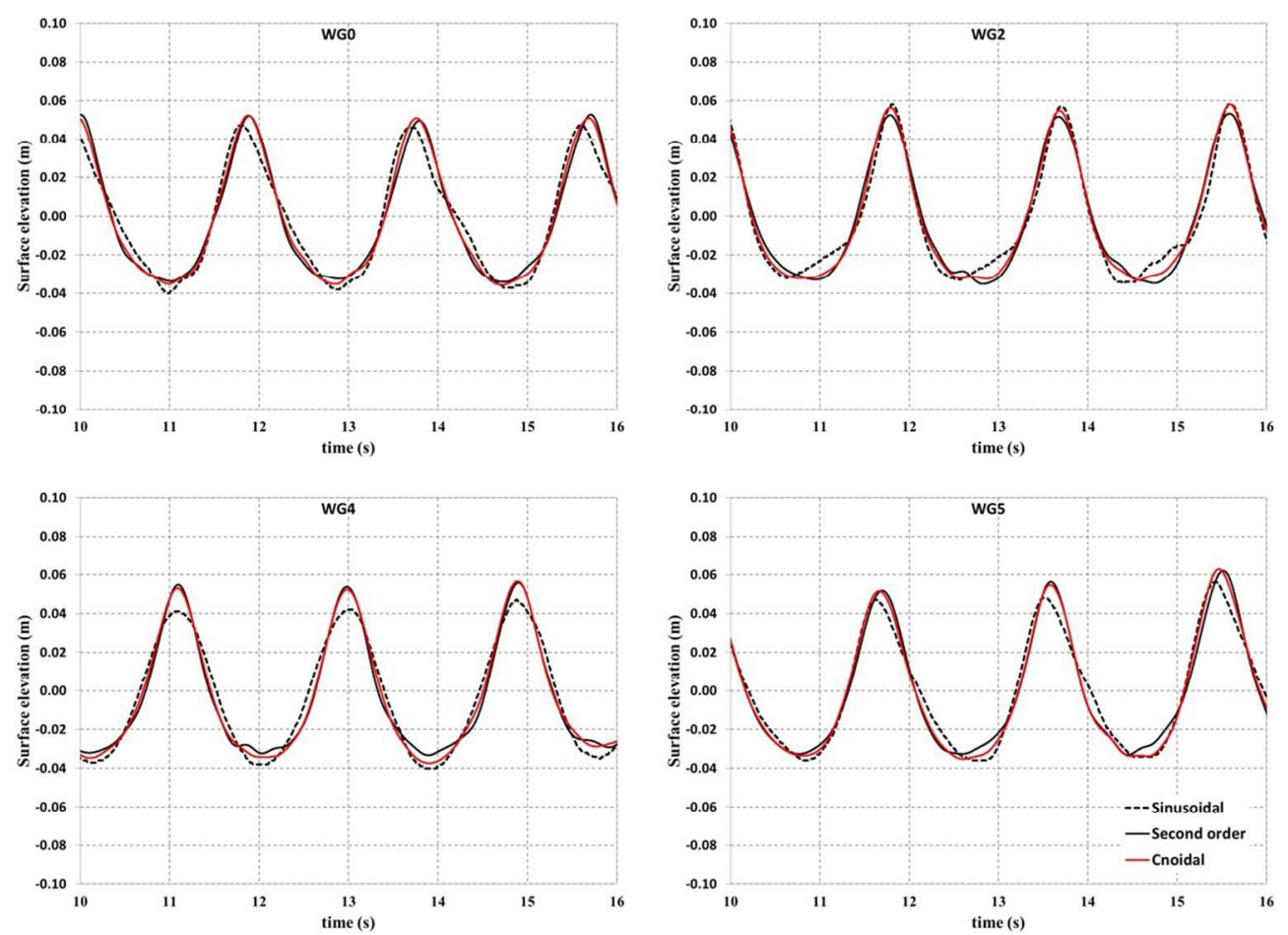

Figure 13 - Comparison of free surface along the numerical flume obtained with three different wavemaker theories. Wave case $3, \mathrm{Ur}=25.4, \mathrm{~h} / \mathrm{L}=0.10$.

\section{$213 \times 154 \mathrm{~mm}(150 \times 150 \mathrm{DPI})$}



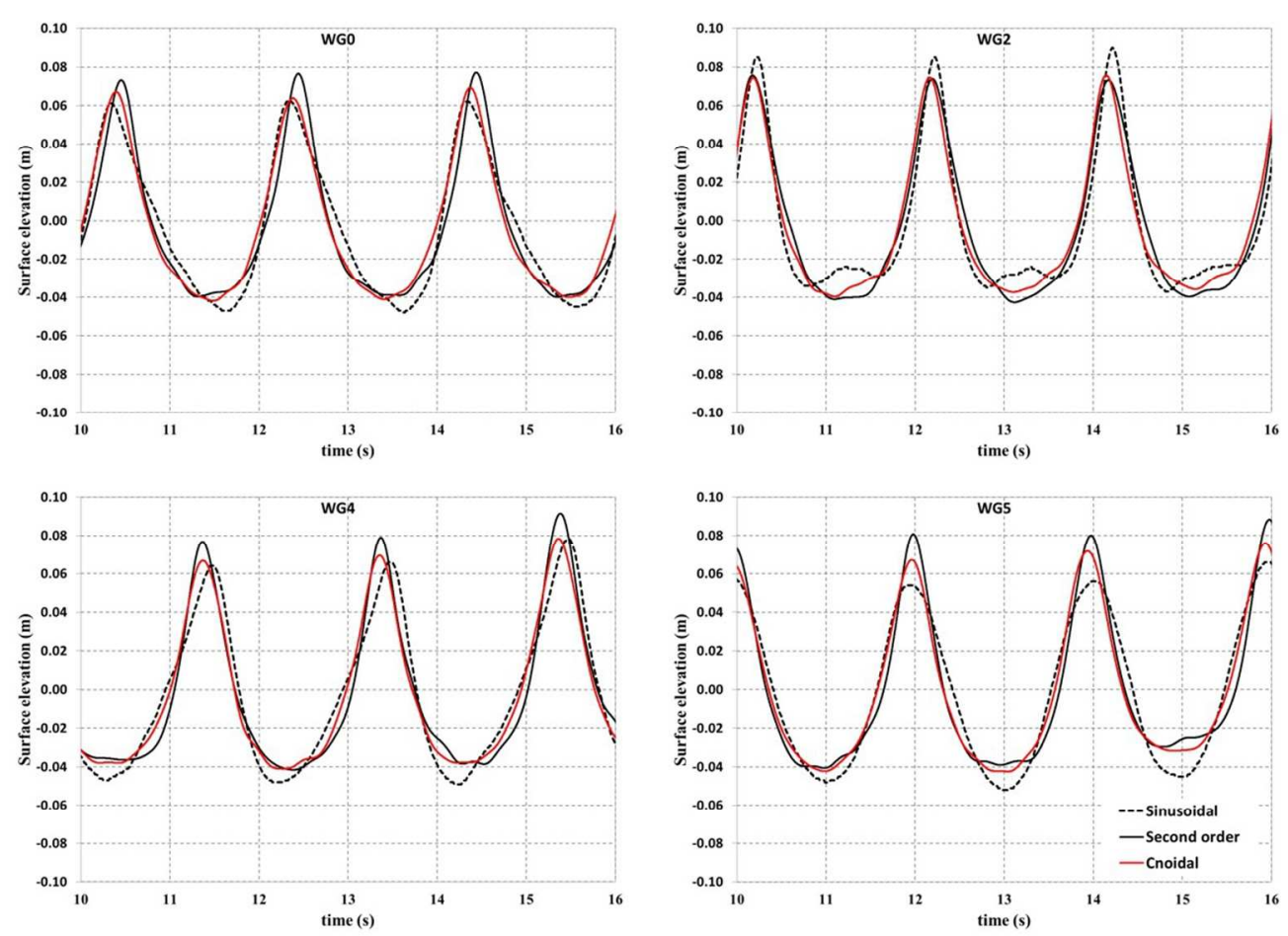

Figure 14 - Comparison of free surface along the numerical flume obtained with three different wavemaker theories. Wave case $2, \mathrm{Ur}=35.0, \mathrm{~h} / \mathrm{L}=0.10$.

$214 \times 154 \mathrm{~mm}(150 \times 150 \mathrm{DPI})$ 

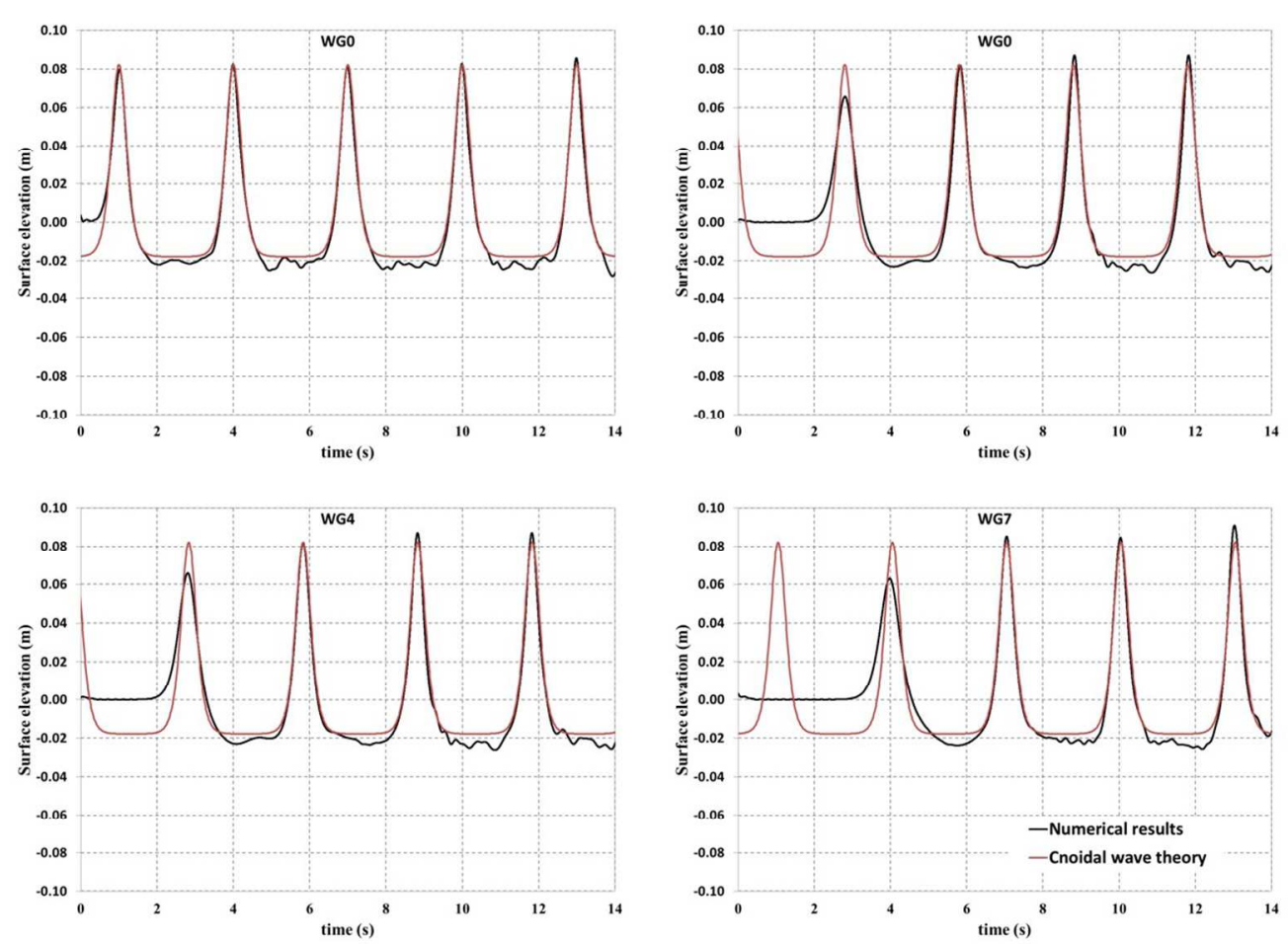

Figure 15 - Numerical and theoretical free surface comparison at four different locations. Wave case Cn01, $\mathrm{Ur}=136, \mathrm{~h} / \mathrm{L}=0.05$.

$214 \times 155 \mathrm{~mm}(150 \times 150 \mathrm{DPI})$ 

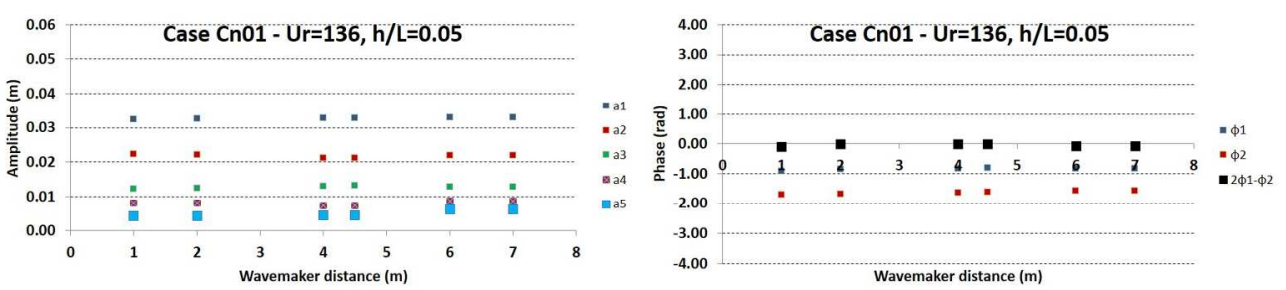

Figure 16 - Amplitude and phase of five first harmonics along the numerical wave flume. Wave generated with a wavemaker theory based on cnoidal wave theory.

$$
335 \times 76 \mathrm{~mm}(150 \times 150 \mathrm{DPI})
$$



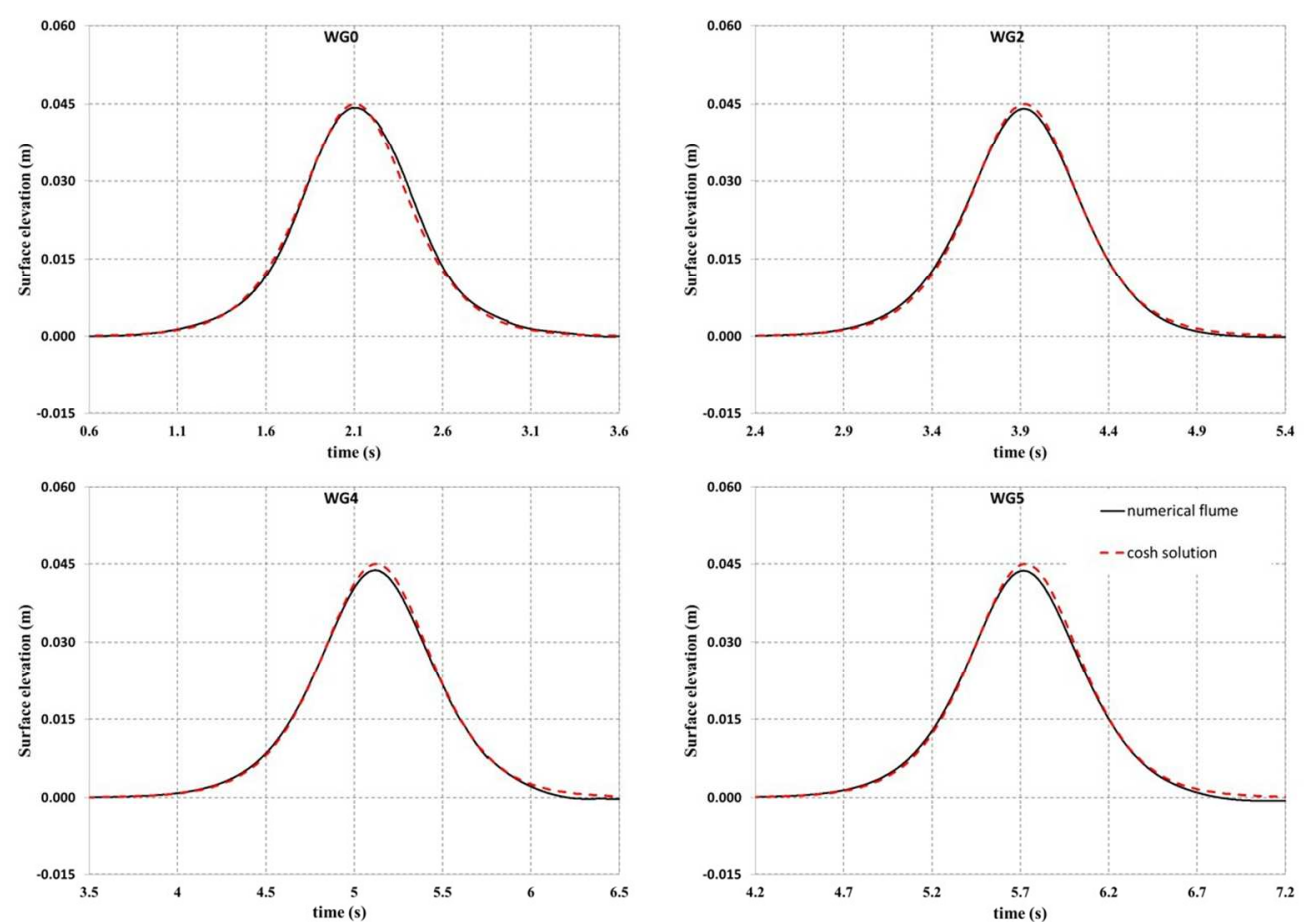

Figure 17 - Comparison between the free surface evolution obtained with the numerical wave flume and the free surfaces obtained with the Boussinesq-type solution (cosh solution). Wave case S01, H=0.045m, $\mathrm{h}=0.25 \mathrm{~m}$.

$215 \times 152 \mathrm{~mm}(150 \times 150 \mathrm{DPI})$ 